\title{
Cortical auditory disorders: a case of non-verbal disturbances assessed with event-related brain potentials
}

\author{
Sönke Johannes*, Michael E. Jöbges, \\ Reinhard Dengler and Thomas F. Münte \\ Department of Neurology, Medical School \\ of Hannover, 30623 Hannover, Germany
}

Received 9 March 1998

Revised 20 March 1998

\begin{abstract}
In the auditory modality, there has been a considerable debate about some aspects of cortical disorders, especially about auditory forms of agnosia. Agnosia refers to an impaired comprehension of sensory information in the absence of deficits in primary sensory processes. In the non-verbal domain, sound agnosia and amusia have been reported but are frequently accompanied by language deficits whereas pure deficits are rare. Absolute pitch and musicians' musical abilities have been associated with left hemispheric functions. We report the case of a right handed sound engineer with the absolute pitch who developed sound agnosia and amusia in the absence of verbal deficits after a right perisylvian stroke. His disabilities were assessed with the Seashore Test of Musical Functions, the tests of Wertheim and Botez (Wertheim and Botez, Brain 84, 1961, 19-30) and by event-related potentials (ERP) recorded in a modified 'oddball paradigm'. Auditory ERP revealed a dissociation between the amplitudes of the P3a and P3b subcomponents with the P3b being reduced in amplitude while the $\mathrm{P} 3 \mathrm{a}$ was undisturbed. This is interpreted as reflecting disturbances in target detection processes as indexed by the P3b. The findings that contradict some aspects of current knowledge about left/right hemispheric specialization in musical processing are discussed and related to the literature concerning cortical auditory disorders.
\end{abstract}

Keywords: Audition, music, cortical auditory disorders, sound agnosia, amusia, event-related potentials, $\mathrm{P} 3 \mathrm{~b}$

\footnotetext{
${ }^{*}$ Corresponding author: Dr. S. Johannes, Department of Neurology, Medical School of Hannover, 30623 Hannover, Germany. Tel.: +495115322023, +49511 5323578; Fax: +495115323115; E-mail: johannes@vm.mhrz.mh-hannover.de.
}

\section{Introduction}

Disorders which are characterized by an impaired comprehension of incoming sensory information in the absence of deficits in primary sensory processes have been termed agnosias. Visual, somatosensory and auditory forms of agnosia have been known since the end of the last century (e.g., $[5,15,19,40,43,44,46,59$, $64,71,77,81,89])$. In the auditory modality, there is a considerable debate about the different subtypes of deficits and hence the underlying mechanisms of auditory information processing. Different disabilities have been described ranging from cortical deafness (e.g., $[7,46])$ to a verbal and a non-verbal form of agnosia and amusia. Pure word deafness, the verbal form, has been characterized as an inability to comprehend and repeat speech with preserved ability to identify non-verbal sounds $[3,9,89]$. Sound agnosia, the non-verbal form, refers to the defective recognition of non-verbal sounds and noises $[19,76]$. Amusia refers to expressive or receptive musical dysfunctions $[35,52,56]$. Frequently, there is a considerable overlap between two or more of these syndromes, thus complicating the analysis of neuropsychological and neurophysiological implications.

Concerning the neural representation of musical functions there have been divergent findings. Kimura [31,32] was the first to describe a right hemispheric predominance for non-verbal stimuli. Later, the results of other studies supported these findings. While Auzou et al. [4] recorded EEG-activity during musical discrimination tasks, Zatorre et al. [93] used the positron emission tomography (PET) technique to test musical perceptual functions. Both authors found a found predominantly right hemispheric activation. This neural representation seems to depend upon musical experience because Bever and Chiarello [8] showed 
that musicians preferably use the left hemisphere for the analysis of melodies whereas non-musicians tend to use the right hemisphere. Later studies have supported these findings and also suggest that musicians rely more on left hemispheric functions than nonmusicians [2,6]. A related question is the functional or anatomical correlate of absolute pitch. In a recent publication Schlaug et al. [70] described persons possessing the absolute pitch to show a tendency towards a stronger left-asymmetry of the planum temporale relating the absolute pitch to left hemispheric functions.

To test these previous hypotheses we investigated the auditory functions in a professional sound engineer with a right perisylvian stroke who had possessed the absolute pitch. From the literature it was hypothesised that this person's musical functions were mainly dependent upon intact left hemispheric functions and that thus a right hemispheric lesion would be easily compensated by left hemispheric functions and hence only affect the non-verbal auditory abilities to a minor degree.

\section{Case report}

On July 8, 1994, a 63 year old right handed male, S.M.H., who had a history of smoking a pack of cigarettes a day for 20 years and a 6 year history of brady- and tachycardia developed a left sided weakness. Initially, he was referred to a different hospital where physical examination revealed a severe left sided, predominantly brachiofacial hemiparesis which disabled the patient from walking. A CT scan showed a hypodense lesion in the right perisylvian region which was interpreted as ischemic brain infarct. During the next two weeks, the hemiparesis improved dramatically so that the patient had regained total control over the left side of his body after ten days. Reflexes were slightly pronounced on the left side, whereas the plantar response was flexor on both sides. The patient consistently complained that he was unable to discriminate sounds and that he had lost his musical abilities. He was referred to our hospital for further evaluation nine weeks after the onset of his neurological symptoms. His physical condition had not changed. Prior to investigations consent was obtained according to the declaration of Helsinki.

Pure tone audiometry (Table 1) 9 weeks after the event was within the normal range for the patient's age group and brainstem auditory evoked potentials were of normal latency and amplitude bilaterally indicat-
Table 1

Pure tone audiogram ${ }^{a}$

\begin{tabular}{ccc}
\hline $\begin{array}{c}\text { Frequency } \\
(\mathrm{Hz})\end{array}$ & \multicolumn{2}{c}{ Hearing loss $(\mathrm{dB})$} \\
\cline { 2 - 3 } & left & right \\
\hline 125 & 10 & -10 \\
250 & 10 & -10 \\
500 & 0 & -10 \\
1000 & 0 & 0 \\
2000 & 10 & 0 \\
4000 & 20 & 20 \\
8000 & 20 & 10 \\
\hline
\end{tabular}

${ }^{a}$ Pure tone audiogram obtained 9 weeks after onset of symptoms.

ing intact brainstem auditory pathway function. The electroencephalogram (EEG) showed predominantly alpha activity and a right temporal slowing with theta activity.

\subsection{Magnetic resonance imaging (MRI)}

MRI of the head was obtained 9 weeks after the onset of symptoms. Fig. 1 depicts T1-weighted sequences before and after application of GadoliniumDTPA and the corresponding slice of the Talairach stereotactic atlas [79]. Fig. 2 shows similar slices plus a T2-weighted image of a plane approximately $4 \mathrm{~mm}$ caudal to Fig 1. Three lesions were detected: The first (depicted as 1 in the Fig. 1) was located in the rostral portion of the left gyrus frontalis inferior and subtended approximately $7 \mathrm{~mm}$ in diameter. The second (depicted as 2 in Fig. 2) was located in the left occipital lobe. The third lesion (depicted as 3 in Fig. 2) involved the right perisylvian region (Gyrus temporalis superior, a portion of the precentral Gyrus and subcortical structures of the insula). All lesions were hyperintense on the T2-weighted images. While lesion 1 and 3 were additionally partly hyperintense on the T1-weighted images, only lesion 2 showed enhancement of Gadolinium-DTPA. Therefore, lesion 1 and 3 were interpreted to be ischemic brain infarcts with hemorrhages which were already several (e.g., nine) weeks old. Lesion 2 was diagnosed to be an ischemic lesion of younger age than lesion 1 and 3 .

\subsection{Neuropsychological deficits}

Prior to the ischemia, the patient was the head sound engineer of a large recording studio and had possessed absolute pitch. Although this was never formally tested, musicians and other sound engineers working with him confirmed this ability. He was strongly right 

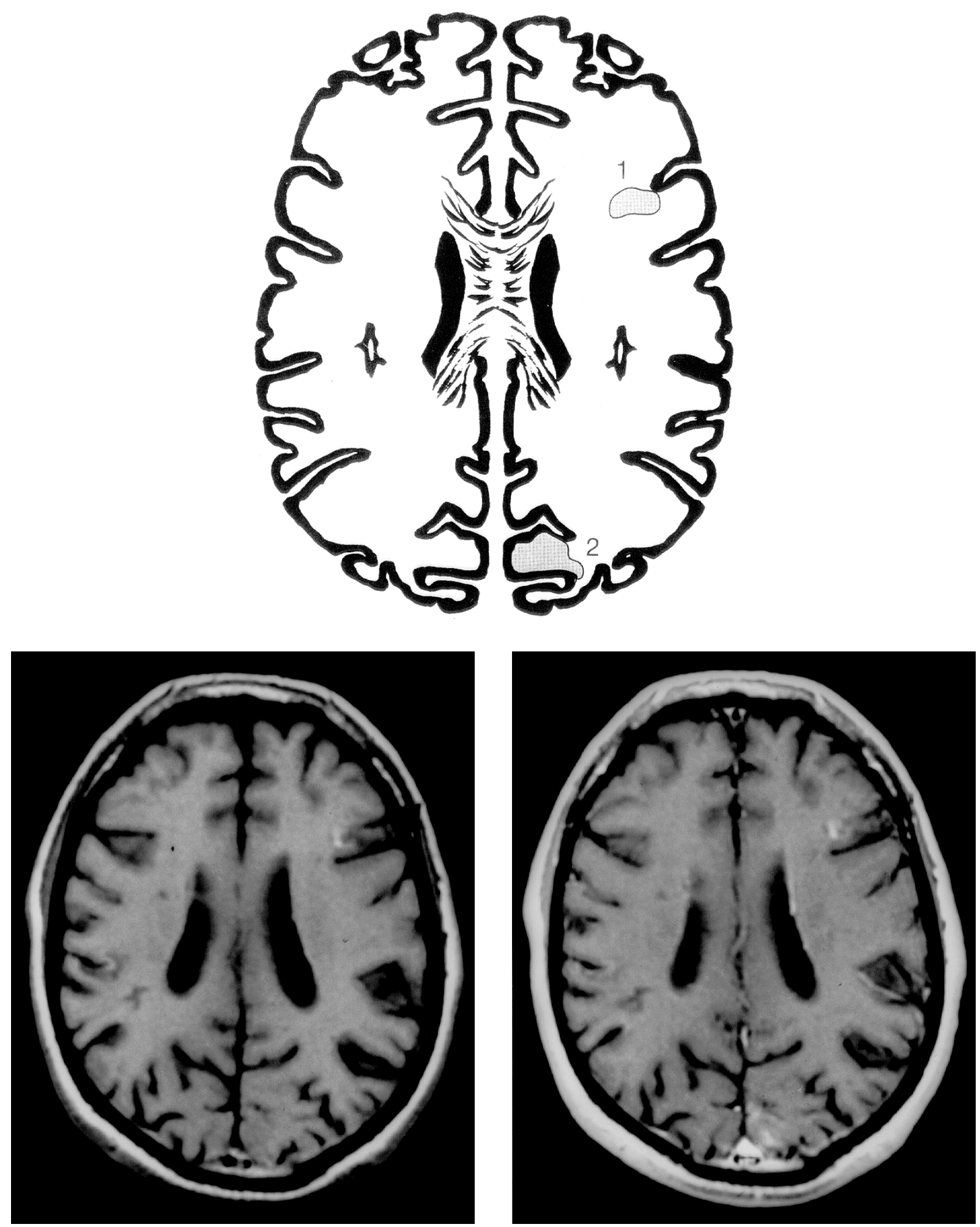

Fig. 1. MRI-scans obtained 9 weeks after the onset of symptoms. Top: According Talairach Slice (slice 113, $24 \mathrm{~mm}$ superior the commisura anterior-commisura posterior (ac-pc) line); bottom left: T1-weighted images before; bottom right: T1-weighted image after the application of Gadolinium-DTPA. There is a left frontal (No. 1) lesion visible. The left hemisphere corresponds to the right side of the MRI. 

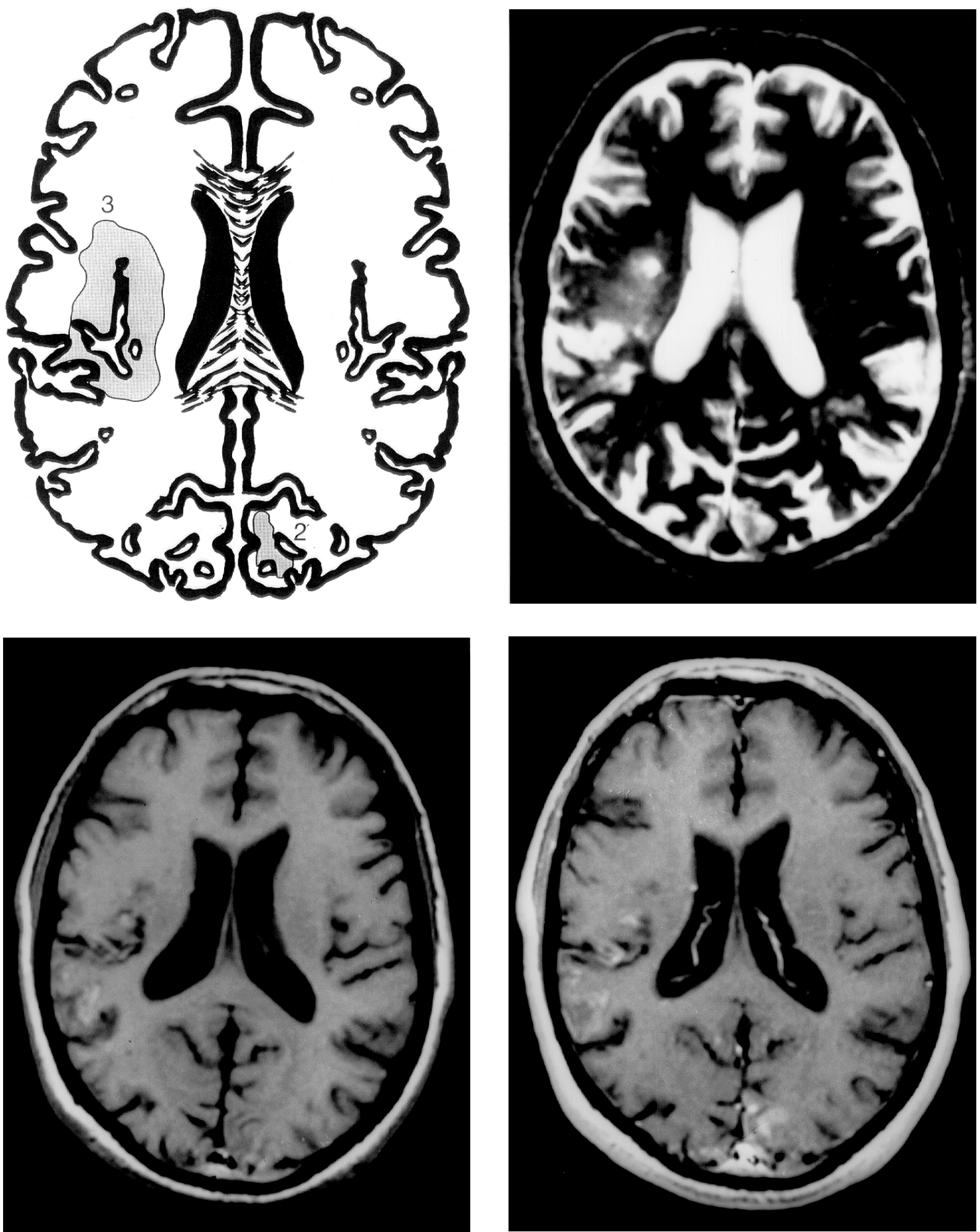

Fig. 2. Similar images as Fig. 1 plus T2-weighted images top right, 1 plane inferior to Fig. 1 (slice 114 of Talairach, 20 mm superior the ac-pc line). The MRI show a left occipital (No. 2) and a right insular (No. 3) lesion. 
handed as assessed by the Edinburgh handedness inventory [51].

Immediately after the incident, the patient reported that he was unable to differentiate smells and that he was frequently disturbed by certain smells which he could not clearly identify (anosmia and kakosmia).

Furthermore, he said that he was unable to understand the meaning of almost all non-verbal sounds which he heard, e.g., he was unable to interpret the sound of a passing motorcycle or of raindrops. Furthermore, he was also unable to perceive music and said that he could not identify a musical piece or musical instruments. From the hospital where the patient was initially treated it was reported that there had been no signs of aphasia or verbal agnosia. During the next 9 weeks the neuropsychological deficits improved only slightly.

Upon first examination in our hospital the patient was found to be of above average intelligence (verbal IQ 108, non-verbal IQ 116, total IQ 112, German version of the WAIS-R) and to have no motor deficit as measured by the finger tapping test [73] (frequency right hand $5.5 \mathrm{~Hz}$, left hand $5.0 \mathrm{~Hz}$; reference right $5.62 \pm 0,95$, left $5.24 \pm 0.91$ ). The Aachen Aphasia Test [26], the standard German test for aphasias, did not reveal any sign of aphasia and there was no evidence for verbal, visual or tactile agnosia or apraxia. Attentional span, spatial orientation, constructional abilities, and calculation were not disturbed.

\subsection{Investigations}

\subsubsection{Recognition of non-verbal sounds}

78 different meaningful, familiar non-verbal sounds (24 indoor sounds, 10 sport sounds, 17 traffic sounds, 15 animal sounds, 12 human noises) were presented 10 weeks and 1 year after the stroke. All sounds were obtained from commercially available compact discs and were presented for at least 10 seconds with the patient's task being to name the sounds. 10 weeks after the stroke the patient was only able to name 23 of the 78 sounds, whereas 1 year after the stroke he correctly named 58 sounds. He tended not to give false responses but instead did not respond at all and was aware of his difficulties. Five age matched control subjects were able to identify a mean of 76.3 sounds.

10 Musical instruments were separately assessed by presenting single instrumental pieces. At the initial examination, the patient correctly named one out of 10 instruments whereas he was able to distinguish the instrument class (e.g., string) in two additional instru-
Table 2 Seashore Test ${ }^{a}$

\begin{tabular}{lccc}
\hline Subtest & \multicolumn{2}{c}{ Performance $(\%)$} & \multirow{2}{c}{$\begin{array}{c}\text { Chance level } \\
(\%)\end{array}$} \\
\cline { 2 - 3 } & 10 weeks & 1 year & \\
\hline Pitch discrimination & 50 & 74 & 50 \\
Loudness test & 46 & 56 & 50 \\
Rhythm test & 53 & 87 & 50 \\
Time test & 52 & 64 & 50 \\
Timbre test & 60 & 86 & 50 \\
Tonal memory test & 50 & 80 & 26 \\
\hline
\end{tabular}

${ }^{a}$ Results of the Seashore Test of Musical Talents performed 10 weeks and 1 year after the stroke. The maximum score is $100 \%$ correct answers.

ments. 1 year after the stroke he correctly named 5 instruments and the instrument class in 2 other instruments. The 5 age matched control subjects were able to name all instruments.

\subsubsection{Musical tests}

Ten weeks and one year after the stroke the Seashore Test for Musical Talents [72] and the test procedure of Wertheim and Botez [85] were administered. The Seashore Test evaluates musical functions in pitch discrimination, loudness, rhythm, time and timbre discrimination and tonal memory. In all subtests of the Seashore Test except the tonal memory test the subject has to give a two-choice answer. Thus, test results of about $50 \%$ correct answers can be obtained by mere guessing. In the subtests for pitch discrimination, loudness, and time the subject had to indicate whether the second tone of a sequence of two given tones is of higher or lower frequency, louder or softer and longer or shorter than the first tone, respectively. In contrast, the rhythm and timbre tests require a decision if the two presented sounds are the same or different. In the tonal memory test, the subject has to detect a fault introduced into the repetition of a sequence of 3 to 5 tones. The test procedure of Wertheim and Botez consists of different subtests examining receptive, productive and semantic musical functions and is described in detail below.

Receptive functions. 10 weeks after the stroke, the patient was barely able to distinguish tones from other presented sounds. Table 2 shows the results of the Seashore Test, which show performance at chance level. In the tests of Wertheim and Botez he showed a strong reduction of receptive functions. He was not able to name simple sounds which were presented alone or in comparison to $\mathrm{C}^{\prime}$ produced by a piano, did not recognize intervals and was not able to differenti- 
ate major or minor chords. He was not able to identify the number of sounds in a chord or identify the intervals composing a chord. Also, he could not describe the tempo of a musical piece or detect tempo or loudness changes which were introduced into well known melodies played on the piano. He did not recognize well known melodies or false notes purposely introduced into a melody. He was unable to write down the notes according to a series of tones played to him on the piano. He could not reproduce a rhythm which was tapped with the reflex- hammer or played to him on the piano. He was also not able to vocally reproduce separate sounds or unknown pieces of music.

Productive functions. These tests were recorded on audio tape and, in addition to the direct analysis, were later evaluated by two musicians which were naive to the purpose of the study.

Although the patient had possessed absolute pitch prior to the stroke, he was unable to vocally produce a sound named by the examiner but instead produced tones which were up to 8 semitones away from the given tone. When asked to produce ascending or descending scales, the patient presented a series of tones of increasing or decreasing pitch, but in no instance was he able to exactly match the correct number of semitones. In trying to vocally reproduce a familiar melody the patient produced sounds which in most instances could be identified by the examiners as the original piece of music, but he introduced gross pitch and rhythm errors.

Prior to the stroke the patient knew how to play the piano. At the time of the evaluation he still knew the general principles of manipulating the instrument, was able to name the parts and to produce simple sounds named by the examiner. Musical pieces which he played could be identified by the examiners but contained pitch and rhythm errors.

Musical reading and writing skills. The functions were intact. The patient was able to name notes on the treble clef which he knew prior to the stroke and he also identified the time value of notes and correctly interpreted auxiliary musical notations. Musical writing assessed by copying a musical text was undisturbed.

\subsection{Follow-up after one year}

1 year after the onset of his neuropsychological deficits the patient reported that his musical talents had improved but that he was still too disabled to work as a sound engineer again.
Receptive functions. Table 2 shows his performance in the Seashore Test 1 year after the stroke. It can be seen that the results of the rhythm test, timbre test and tonal memory test had improved more than performance in the loudness and time subtests which still show performance at about chance level.

The other receptive musical functions had also improved. While the patient still could not name sounds which were presented alone, he correctly named 2 out of 10 tones which were presented with respect to $\mathrm{C}^{\prime}$ produced by a piano. He detected 1 out of 10 presented intervals and correctly classified 7 out of 10 major and minor chords. Furthermore, he correctly identified the number of sounds in a chord in 6 out of 12 presentations (three different presentations each of 2 to 5 sounds). He was still not able to name the interval composing a chord (0 correct, 10 false answers). He was able to indicate whether the tempo of a piece was fast, medium or slow in 5 out of 5 cases and also correctly describe changes in loudness of a melody in all 5 cases. He correctly named 5 well known songs and also detected one purposely introduced error in 4 out of 5 melodies. He could not write down the notes according to a series of tones but was able to imitate 5 out of 5 rhythms which were tapped to him with the reflex-hammer. He was able to imitate 3 out of 5 rhythms which were played on the piano. He was still not able to correctly reproduce a separate sound but instead produced a sound up to 4 semitones away from the given tone. The patient was still not able to reproduce an unfamiliar piece of music.

Productive functions. Being asked to vocally produce a given sound the patient produced tones which were up to 3 semitones away from the given. Also, the ascending and descending scales were still faulty. Singing a familiar melody was better than at the first examination, although the patient still unpurposely introduced some pitch faults into these melodies, while rhythm faults were rare. The patient had regained his ability to play the piano with both hands but infrequently made faults concerning the loudness of tones.

Musical reading and writing remained intact.

\subsection{Dichotic listening tests}

S.M.H. underwent this test 1 year after the stroke in addition to the same 5 control subjects.

\subsubsection{Procedure}

120 two syllable words were randomly ordered to form two lists each containing the same 120 words in 
Table 3

Dichotic listening experiment ${ }^{a}$

\begin{tabular}{lccccc}
\hline Condition & Words & $\begin{array}{c}95 \% \text { confidence } \\
\text { interval }\end{array}$ & Syllables & $\begin{array}{c}95 \% \text { confidence } \\
\text { interval }\end{array}$ & $\begin{array}{c}\text { Numbers } \\
\text { interval }\end{array}$ \\
\hline Left ear alone & 19 & $30-39$ & 11 & $30-39$ & 36 \\
Right ear alone & 32 & $32-40$ & 36 & $31-40$ & $33-40$ \\
Both ears, correct left & 7 & $18-35$ & 12 & $18-33$ & $35-40$ \\
Both ears, correct right & 25 & $20-36$ & 25 & $20-34$ & 21 \\
\hline
\end{tabular}

${ }^{a}$ Patient's results of the dichotic listening experiment performed 1 year after the stroke. The 95\% confidence interval was calculated from the control subjects' performance. Absolute number of correct responses are given, the maximum number of correct responses was always 40 . 'Left', 'right' and 'both ears' refers to attention condition.

a different order. During the test one list each was presented to the left and right ear. It was ensured that the two words which were presented to the opposing ears always began at exactly the same time. They had a mean duration of $520 \mathrm{~ms}$ and the loudness was adjusted to be $70 \mathrm{~dB}$. The task was, on command, to identify the left ear word or the right ear word or both words so that each condition occurred 40 times.

Two other tests were done with similar lists which were constructed from 120 german syllables and 120 german one digit numbers.

\subsubsection{Results}

The results are shown in Table 3. The patient detected less words in the left ear alone condition than in the right ear alone condition. In the both ear condition, he only very rarely detected both simultaneously presented words and more frequently recalled the word from the right ear.

\subsection{Cortical auditory event related potentials (aERP)}

Event-related brain potentials (ERP) were recorded. ERP are minute voltage fluctuations which can be attributed to certain cognitive processes. They can be recorded non-invasively from the human scalp. One of the simplest tasks in which it is possible to record ERP is the so-called 'oddball task'. This involves the presentation of tones of two different frequencies with the subject's task being to detect a target which is one of the two tones. These targets evoke a sequence of enhanced ERP components.

\subsubsection{Procedure}

The first session was recorded 10 weeks after the stroke (session 1) and the second session took place 1 year afterwards (session 2). The stimuli consisted of computer generated sinusoidal tones of $1000 \mathrm{~Hz}$ and $750 \mathrm{~Hz}$. In addition, 30 'novel' stimuli were in- cluded that consisted of digitized and computer-edited environmental sounds (e.g., a dog's bark, honking of a car). The tones were presented to both ears using headphones at $80 \mathrm{~dB}$ SPL, had durations of $50 \mathrm{~ms}$ and $10 \mathrm{~ms}$ rise and fall times with an interstimulus interval of 2 seconds. One of the sinusoidal tones was designated as the target $(p=0.15)$ and the other sinusoidal tone the standard $(p=0.7)$. Novel tones were presented with a probability of $p=0.15$. As only 30 novel tones were available, some were repeated. An experimental run consisted of 300 stimuli presented in random order. The patient's task was to respond to the target tones as quickly and as accurately as possible by pressing a button held in the right hand.

\subsubsection{Apparatus}

In all sessions, the EEG was recorded to yield approximately 320 target tones each after artifact rejection. 20 EEG channels were recorded with reference to the right mastoid according to the international 10-20 system [27]. Biosignals were amplified with a timeconstant of 10 seconds, low-pass filtered $(100 \mathrm{~Hz})$ and $\mathrm{AD}$-converted with $4 \mathrm{~ms}$ resolution. Blinks and eye movements were monitored with electrodes located besides and below the right eye and prior to averaging an artifact rejection procedure was used to exclude trials contaminated with eye movements or amplifier blocking.

\subsubsection{Subjects}

In addition to the patient 5 age-matched right handed male control subjects who did not possess absolute pitch were also examined once with the same procedure. They had the same socioeconomic status as the patient and, although they were not formally tested, were estimated to have the same IQ as the patient. The visual acuity was normal or corrected to normal. All control subjects used their right hands for responses. 


\subsubsection{Analysis}

The amplitudes of the N1, P3a and P3b ERPcomponents were measured as mean amplitudes centered around their mean peak latencies in case of the $\mathrm{N} 1$ and P3a components. The amplitude of the P3b was measured as the mean amplitude in the period subtending 300-700 ms post stimulus. The latencies were measured as peak latencies in case of the N1 and P3a components and as the time to reach half of the mean amplitude in the 300-700 ms interval in case of the P3b.

The behavioural results and the electrophysiological data were subjected to a statistical analysis. For this purpose the $95 \%$ confidence interval (CI) was calculated from the control subjects' data. The patient's data were considered to be significantly different from the control subjects' if they fell outside the CI. The electrophysiological data were compared electrode by electrode. This means that, for example, the patient's ERPs at electrode $\mathrm{C} 4$ were related to the CI which resulted from the same measurements in the control subjects at electrode $\mathrm{C} 4$. To also account for possible hemispheric asymmetries a left-right ratio (1-r ratio) was calculated by dividing the patient's left hemispheric measures by the related right hemisphere measures (e.g., calculating C3/C4). ${ }^{1}$

To analyze the scalp distributions of the early N1 ERP-components isovoltage maps were calculated. They provide a reference-free estimate of the cortical activation over a given time period. This period was chosen as a $50 \mathrm{~ms}$ timewindow which was centered upon the N1 peak-latency. A dipole source analysis of the N1 component (BESA, [69]) was used to generate and test hypotheses about possible voltage dipoles generating the N1 component.

\subsubsection{Results}

Hit rates and reaction times of the patient and of the control group are shown in Table 4. The patient's responses were within the normal range.

N1 component. Fig. 3 shows the aERP to standard stimuli of the patient and of the controls. In both groups, the prominent $\mathrm{N} 1$ peak had a fronto-centrally maximum. The peak latency of the patient recordings (152 ms) was longer than of the control subjects (CI: 100-124 ms). At the electrode F4 the amplitude of the

\footnotetext{
${ }^{1}$ Electrodes over the left hemisphere are labeled with odd numbers whereas electrodes over the right hemisphere have even numbers.
}

Table 4

Response characteristics ${ }^{a}$

\begin{tabular}{lcccc}
\hline $\begin{array}{l}\text { Time of } \\
\text { examination }\end{array}$ & $\begin{array}{c}\text { RT } \\
(\mathrm{ms})\end{array}$ & $\begin{array}{c}95 \% \\
\text { confidence } \\
\text { interval }\end{array}$ & $\begin{array}{c}\text { HR } \\
(\%)\end{array}$ & $\begin{array}{c}95 \% \\
\text { confidence } \\
\text { interval }\end{array}$ \\
\hline 10 weeks & 424 & $403-458$ & 91.5 & $91.0-100$ \\
1 year & 402 & $403-458$ & 95.6 & $91.0-100$ \\
\hline
\end{tabular}

${ }^{a}$ Reaction times (RT) and hit rates (HR) of the patient's responses to targets during the recording auf auditory event-related potentials. The $95 \%$ confidence interval was calculated from the control subjects' performance.

$\mathrm{N} 1$ was slightly reduced (F3 $5.1 \mu \mathrm{V}, \mathrm{CI}: 4.4-5.6 \mu \mathrm{V}$; F4 $4.05 \mu \mathrm{V}$, CI: 4.2-5.5 $\mu \mathrm{V})$. This effect also resulted in a significant left-right asymmetry of the patient's waveforms.

However, the isovoltage maps of the N1 (Fig. 4) did not yield large differences of cortical activation between control group and patient at the time of the $\mathrm{N} 1$. Within the same timeperiod, the BESA-analysis revealed that $96.5 \%$ of the control subjects variance could be explained by two dipoles which were located within the upper medial temporal lobes pointing upward and medial (Fig. 4). Testing this solution within the timerange of S.M.H.'s N1 component it was able to explain $94.7 \%$ of the variance.

P3a component. AERP to novel stimuli are shown in Fig. 5. After the initial N1 deflection there is a positive component in the timerange from $250 \mathrm{~ms}$ to $500 \mathrm{~ms}$. This component, the P3a, shows a central maximum. The latencies of the patient's P3a were within the confidence intervals as well as were the amplitudes over the left hemisphere. In contrast, over the right hemisphere the amplitudes were slightly reduced at the electrode sites F4 and C4. This also resulted in a significant left-right asymmetry at these sites.

P3b component. AERP to targets are depicted in Fig. 6.

At frontal and central electrodes, between 200 and $300 \mathrm{~ms}$ post stimulus, the control subjects show a N2 component which cannot clearly be seen in the patient's recordings. In case of the control subjects, the $\mathrm{N} 2$ is followed by the positive P3b component between 300 and $700 \mathrm{~ms}$ post stimulus. It strikes that S.M.H. did not generate a P3b 10 weeks after the stroke (the $\mathrm{P} 3 \mathrm{~b}$ amplitude was well below the CI at P3 and P4). In contrast, one year after the stroke this difference had vanished and at $\mathrm{P} 3$ and $\mathrm{P} 4$ the $\mathrm{P} 3 \mathrm{~b}$ amplitude fell within the CI. In parallel, over C3 and C4, the P3b amplitude was larger than in the control group one 


\section{Standard stimuli}
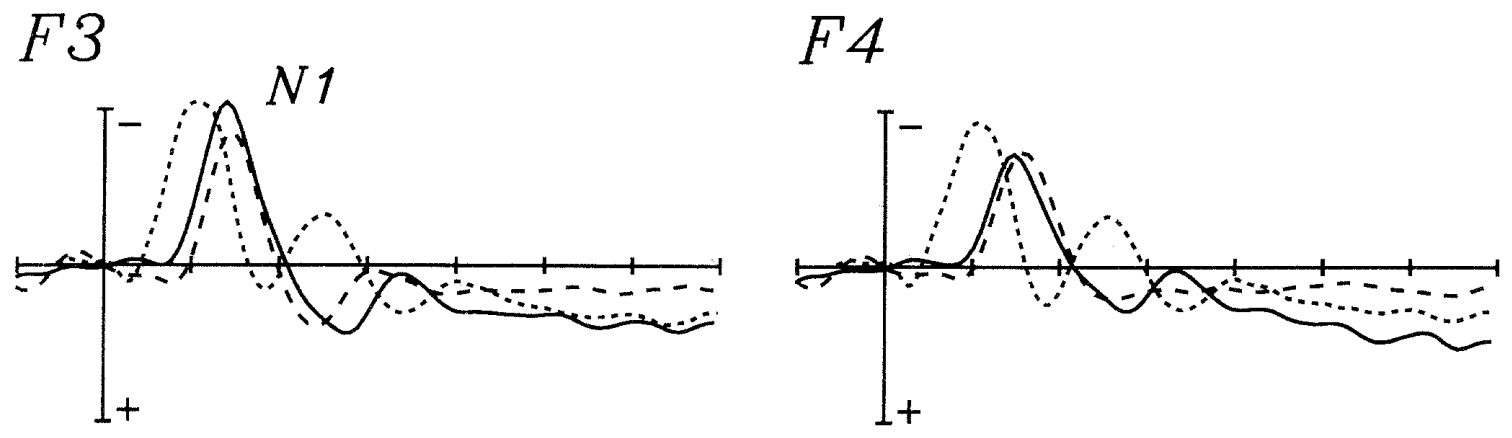

C3

C4
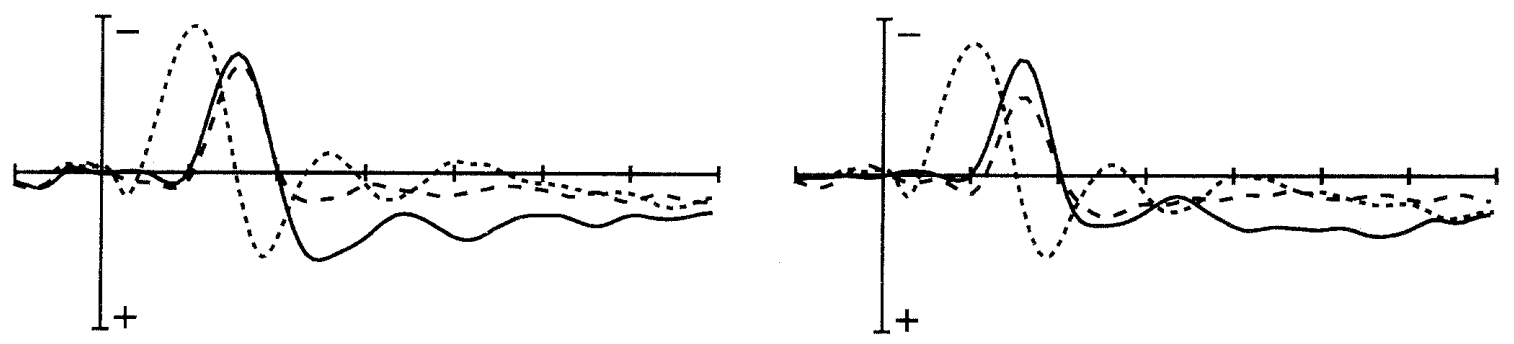

P3

P4
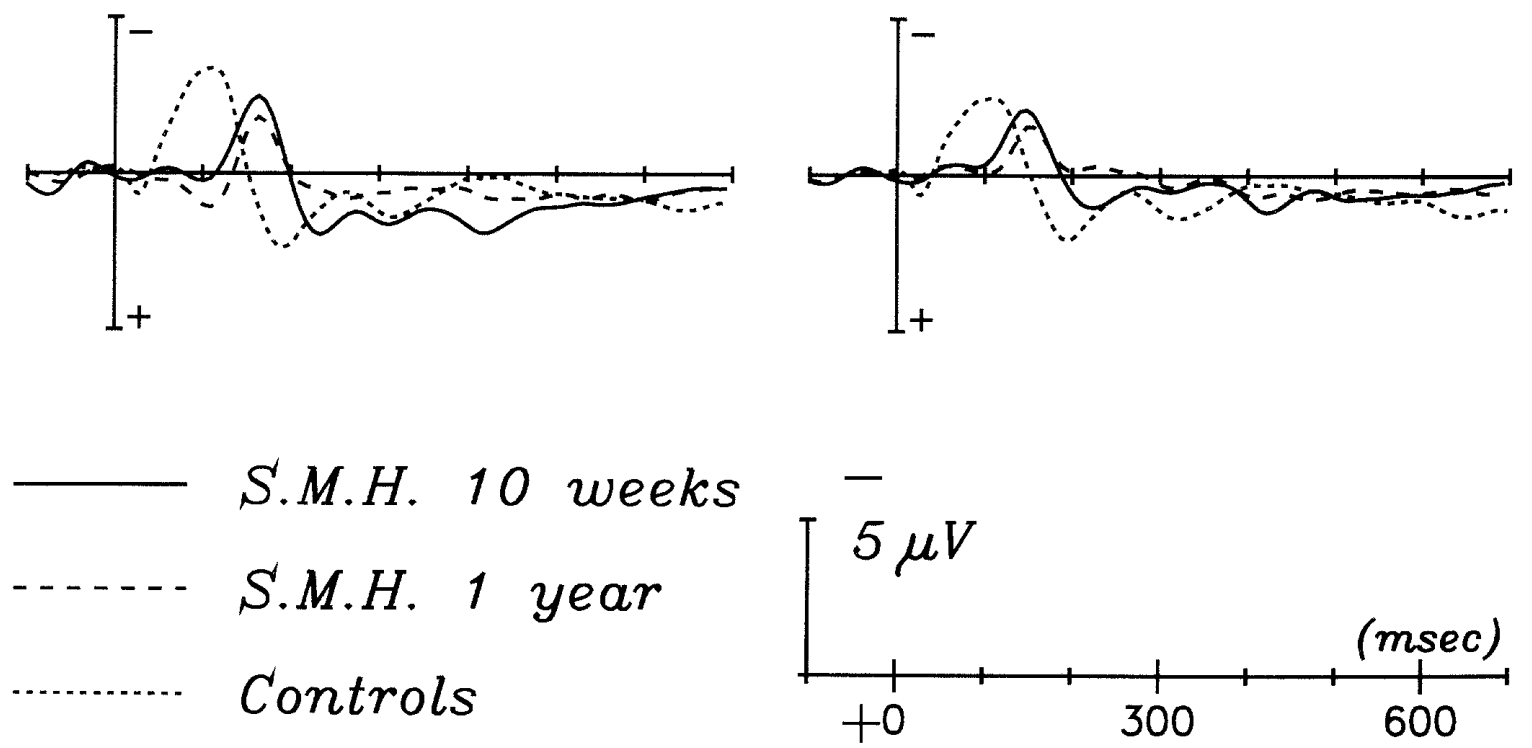

Fig. 3. Auditory event-related N1-potentials to standards at frontal and central scalp sites: Two patient recordings and grand-average waveform to control subjects $(n=5)$ are shown. Left hemisphere: odd electrode numbers, right hemisphere: even numbers. 


\section{ISOVOLTAGE MAPS}

\section{N1- component \\ (standard stimuli)}

\section{CONTROLS}

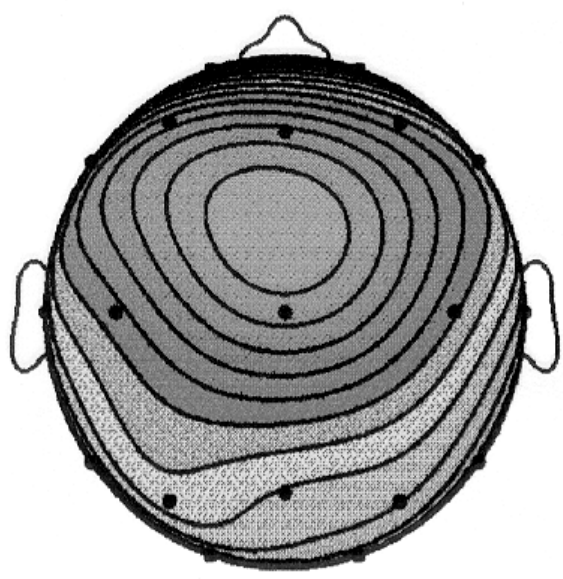

S.M.H.

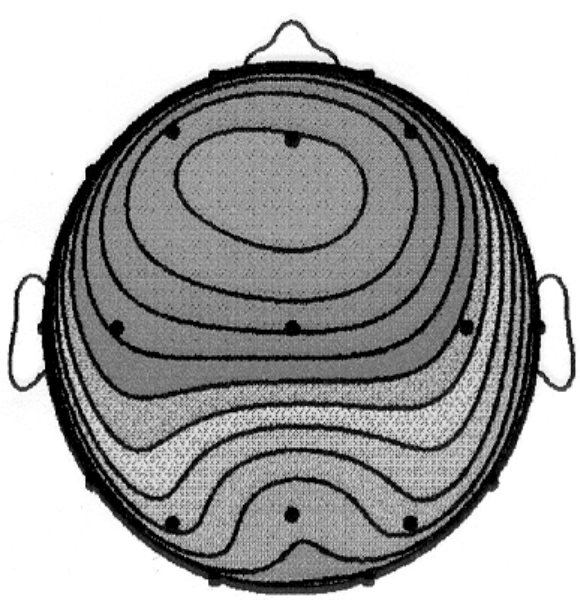

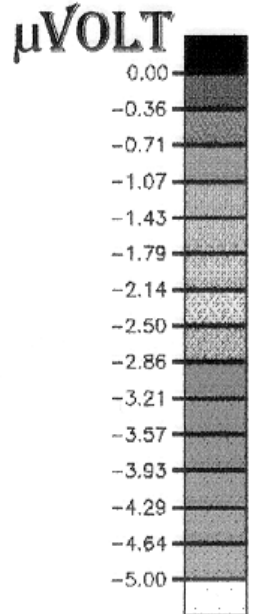

\section{DIPOLE SOURCES}
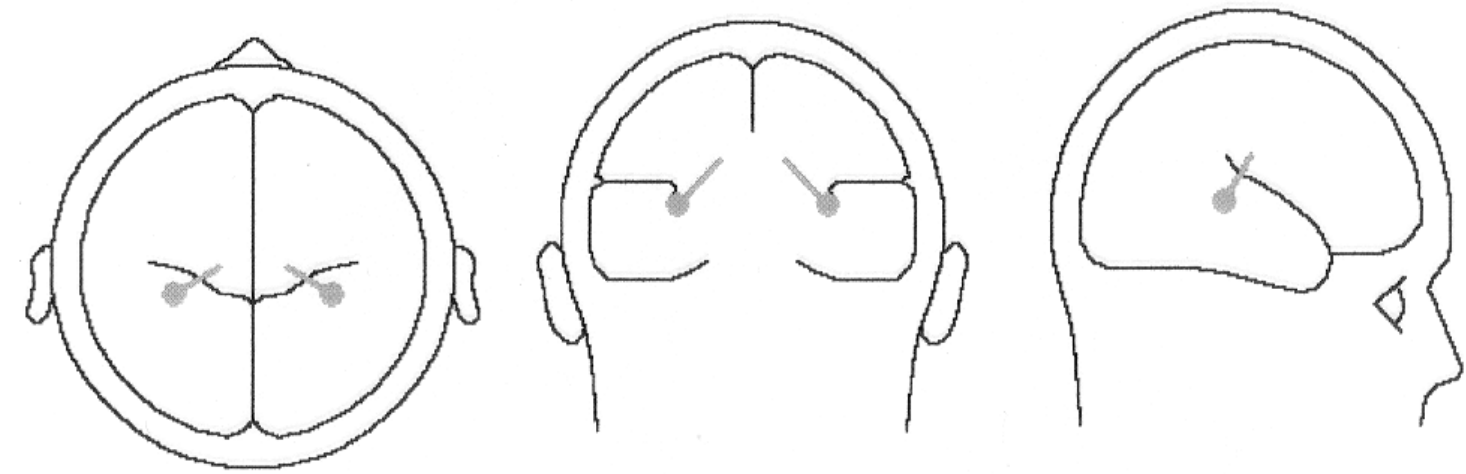

\section{Residual Variance}

Controls $3.5 \%$

\section{S.M.H. $5.3 \%$}

Fig. 4. Top: Isovoltage Maps of the N1 component. The timewindows subtended $50 \mathrm{~ms}$ and were centered upon the N1 peak latency. Bottom: Brain Electric Source Analysis (BESA) solution of the control subjects' N1 component (residual variance 3.5\%). Using this solution upon S.M.H.'s N1 component the residual variance is $5.3 \%$. 


\section{Novel stimuli}

F3

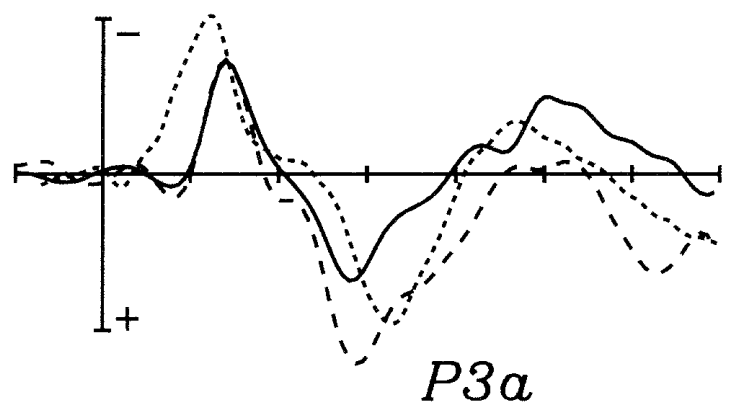

C3

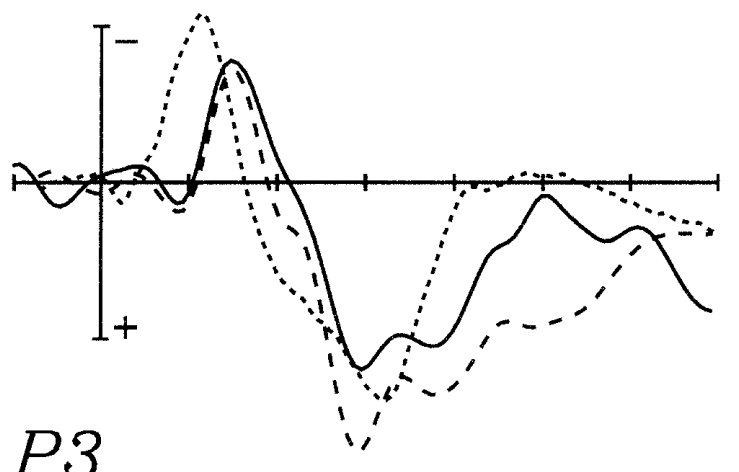

P3

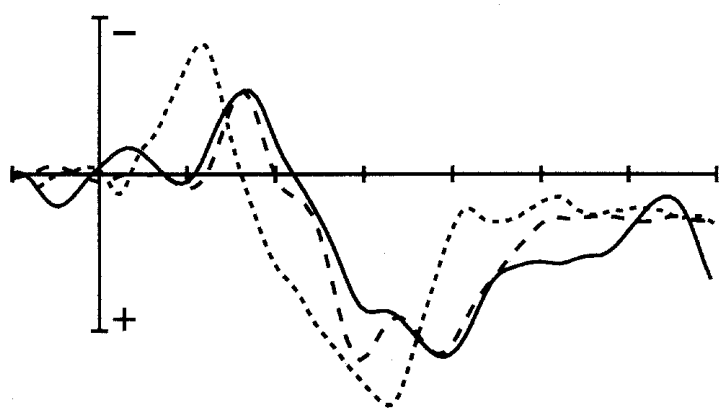

S.M.H. 10 weeks

S.M.H. 1 year

\section{Controls}

F4

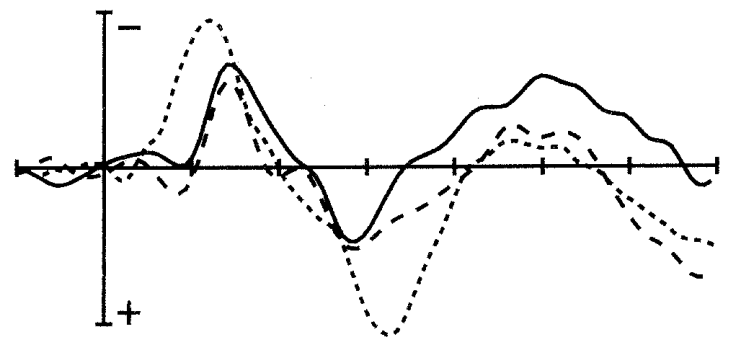

C4

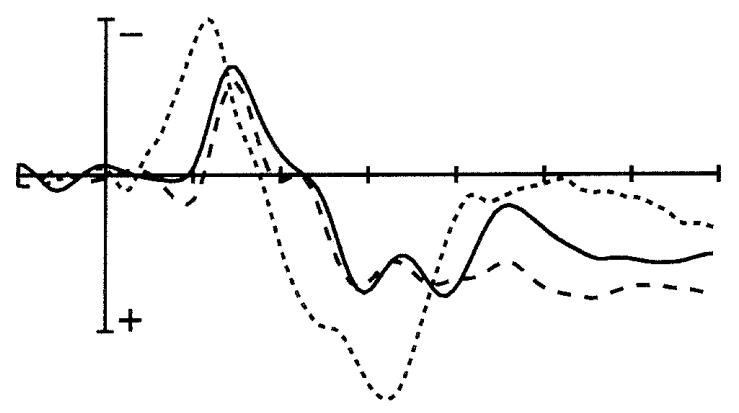

P4
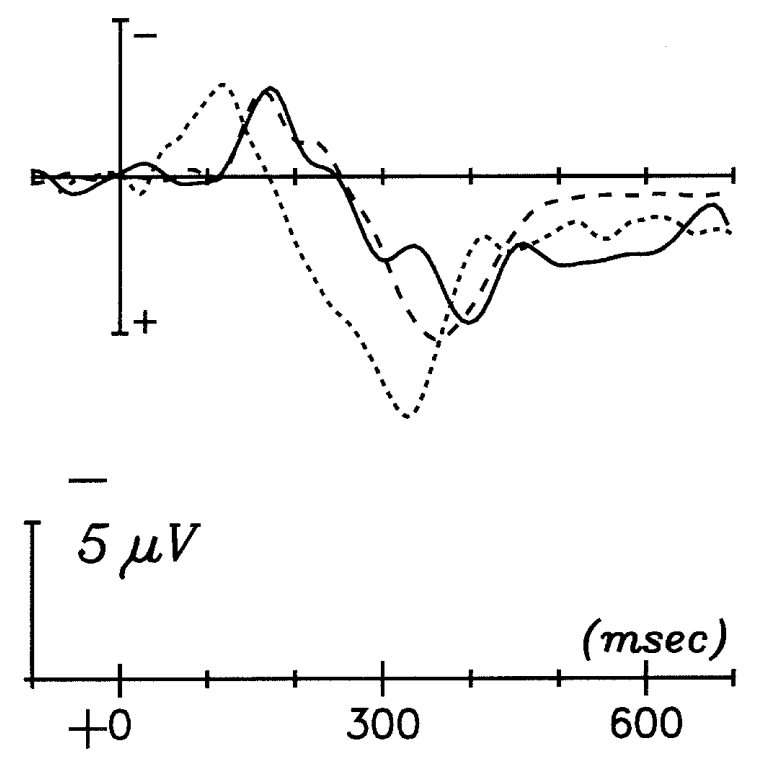

Fig. 5. Auditory event-related P3a-potentials to novels. The patient's P3a is slightly reduced at the frontal and central electrodes of the right hemisphere. 


\section{Target stimuli}

F3

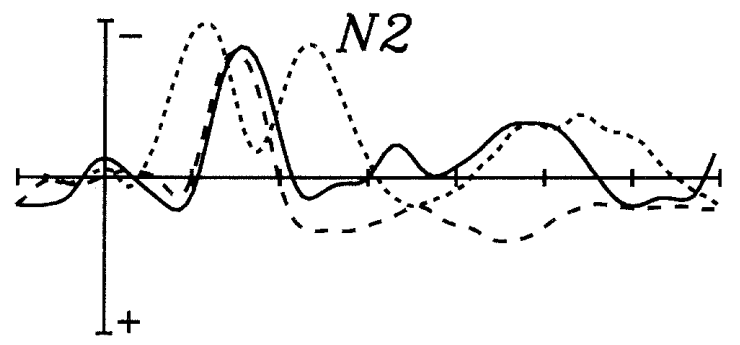

C3
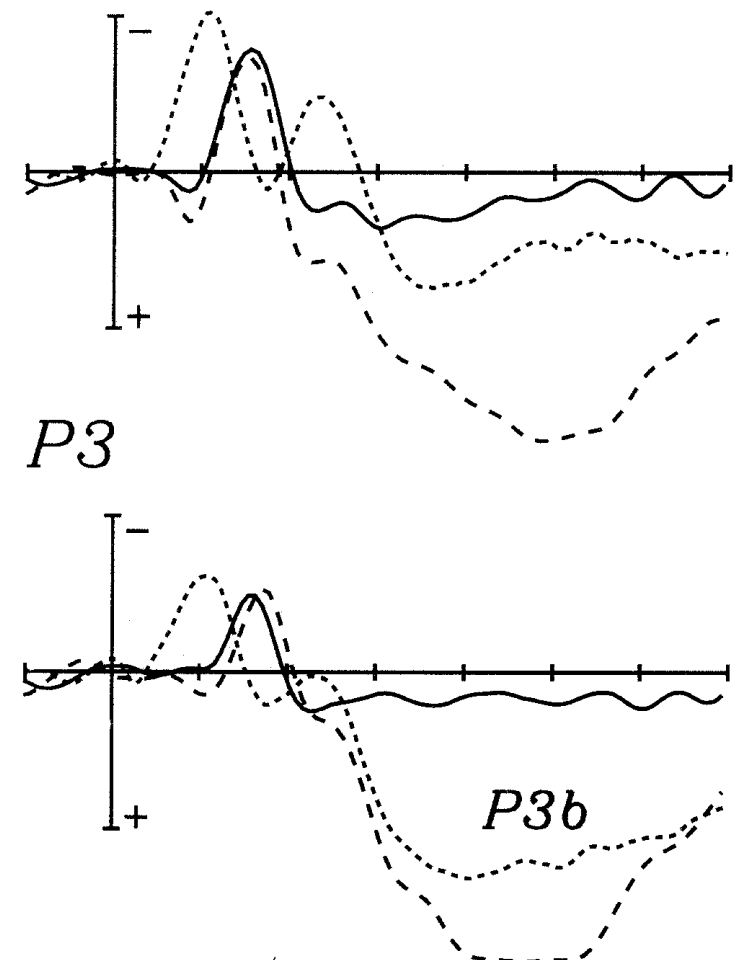

S.M.H. '10 weeks

-....... 1 year

\section{Controls}

F4

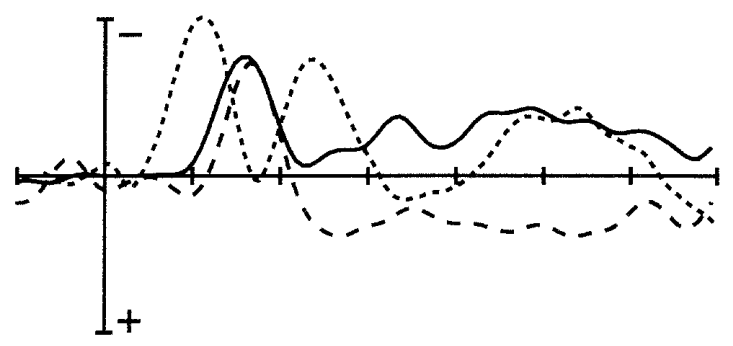

C4
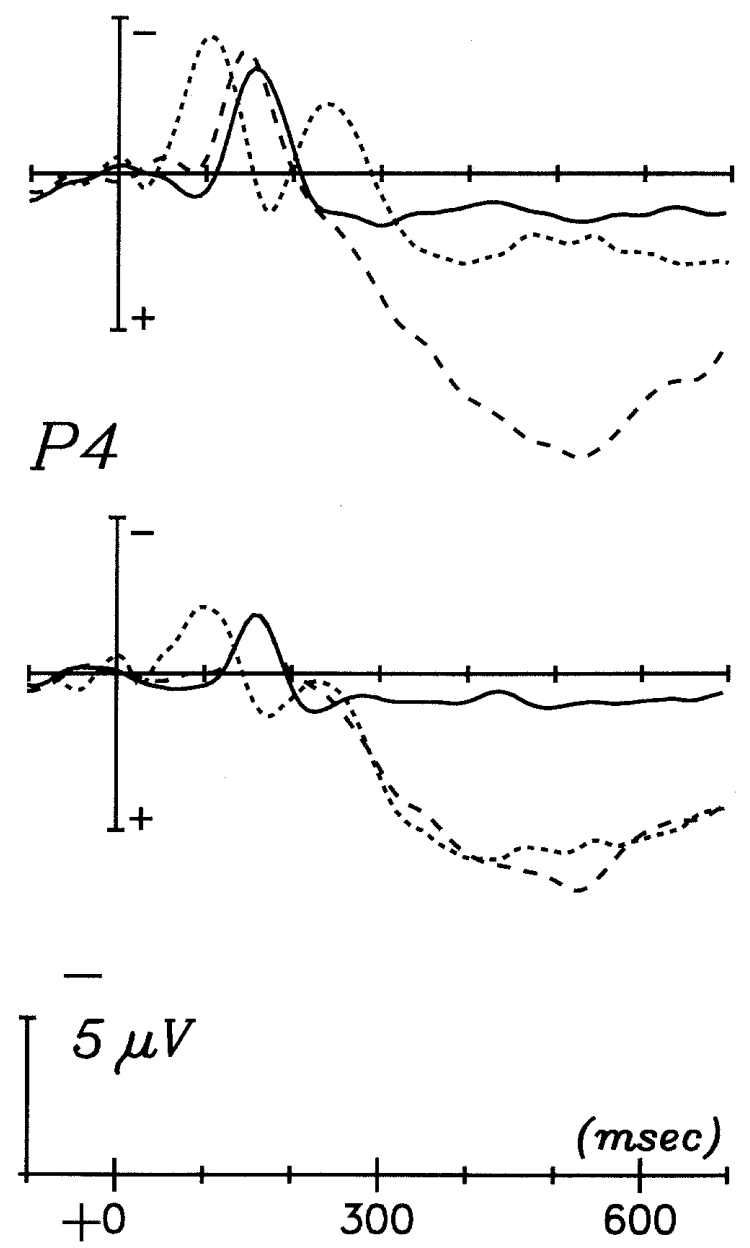

Fig. 6. Auditory event-related N2- and P3b-potentials to detected targets. The patient's P3b is absent 10 weeks after the stroke but returns 1 year later. 
year after the stroke (the P3b was above the CI at $\mathrm{C} 3$ and $\mathrm{C} 4$ ). This reflected that the generator of the P3b was located more anterior in S.M.H. than in the control group. There were no significant hemispheric differences.

\subsection{Cortical visual evoked potentials (vERP)}

\subsubsection{Procedure}

The vERP were recorded from the patient 10 weeks after the stroke and also from the same 5 control subjects. The patient's recording one year after the stroke was lost due to technical error. The stimuli consisted of circles and crosses which subtended 0.5 degrees of visual angle and which were serially presented white on a dark gray background in the center of a video screen. The duration of presentation was $100 \mathrm{~ms}$, the inter-stimulus interval was a random between 900 and $1700 \mathrm{~ms}$ (rectangular distribution). The task was to indicate the presence of a circle (probability $p=0.25$ ) on the screen by pressing a button. The number of runs was calculated to yield approximately 100 targets after artifact rejection procedures per average. The technical aspects of ERP recording were the same as in the auditory condition.

\subsubsection{Results}

Fig. 7 shows the ERP of patient's session 1 and of the control subjects. It can be seen that after the initial deflections there is a large positive $\mathrm{P} 3 \mathrm{~b}$ component between 300 and $600 \mathrm{~ms}$ post stimulus. This P3b has a centro-parietal distribution and does not differ between the patient's recording and the controls'. Because the early components are known to show a large interindividual variety at the parietal scalpsites they were not subjected to further analysis.

\section{Discussion}

While S.M.H. had possessed absolute pitch, he showed a persistent auditory deficit and a disturbed perception of odors after a stroke. The main findings were a severe deficit in the recognition of non-verbal sounds and a deficit of receptive and productive musical functions in the absence of any sign of reduced language abilities. For at least several months, the patient was barely able to discriminate environmental sounds and musical instruments. Furthermore, he was unable to perceive music itself, to recognize familiar tunes and to discriminate unfamiliar tunes on the basis of pitch or rhythm differences. Other receptive musical functions such as loudness or time discrimination were also grossly impaired. The productive functions were also affected but the semantic musical functions were preserved. In the course of the disease both, sound recognition and musical functions improved, with rhythmic functions improving more than functions related to pitch.

The patient's audiogram and the auditory brainstem evoked responses were normal. Thus, his disability cannot be attributed to a primary hearing disturbance but instead has to be of cortical origin. The cortical auditory processes consist of a series of serial and partly parallel processes which range from the primary evaluation of auditory information within the primary auditory cortex to conscious perception and evaluation of the sounds. This case can help to characterize the neuroanatomical correlates and the temporal patterns of these processes.

\subsection{Neuroanatomical considerations}

One large right perisylvian lesion and two smaller lesions located in the right occipital and left frontal lobes were identified in S.M.H. by MRI. Clinically, S.M.H.'s auditory deficit paralleled the onset of a severe left hemiplegia. In addition, the dichotic listening experiments performed one year after the onset of symptoms showed a strong advantage for the right ear, indicating a possible persistent impairment of predominantly right temporal (left ear) functions. Furthermore, the patient was strongly right handed due to the Edinburgh Handedness Inventory with a corresponding left hemispheric presentation of language. Thus, clinically, due to the lack of any signs of aphasia in this patient and due to the results of the dichotic listening experiment, there is evidence for right but not for left hemispheric dysfunction corresponding with the large right perisylvian stroke. The effects of the two other small cortical lesions are less clear. The frontal lobes have been associated with a variety of functions ranging from the identification of odors to attentional processes and to emotion (e.g., [29, 37, 38]). However, the neuropsychological testing did not show any attentional disorders and the patient did not report any personality change. It has to remain unclear if S.M.H.'s defect in odor perception is related to the frontal lesion because there are experimental results showing that not only left frontal regions are involved in this task. For example, Zatorre and Jones-Gotman [92] described a right nostril advantage for the discrimi- 


\section{Visual target stimuli}

P3

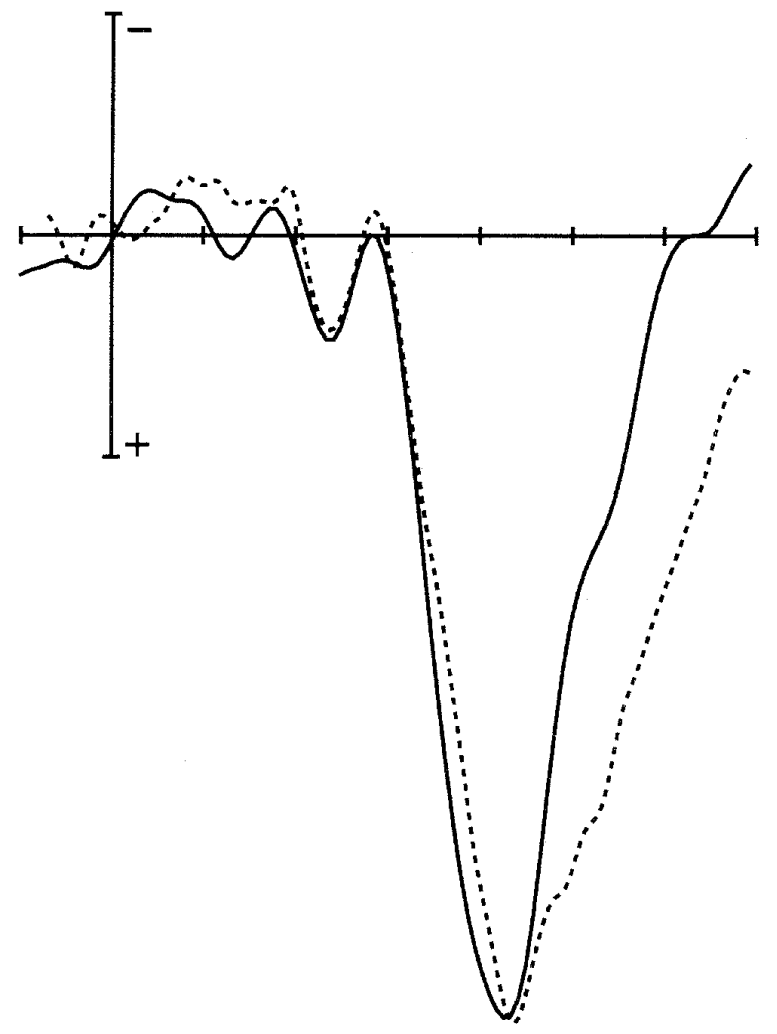

P3b
P4

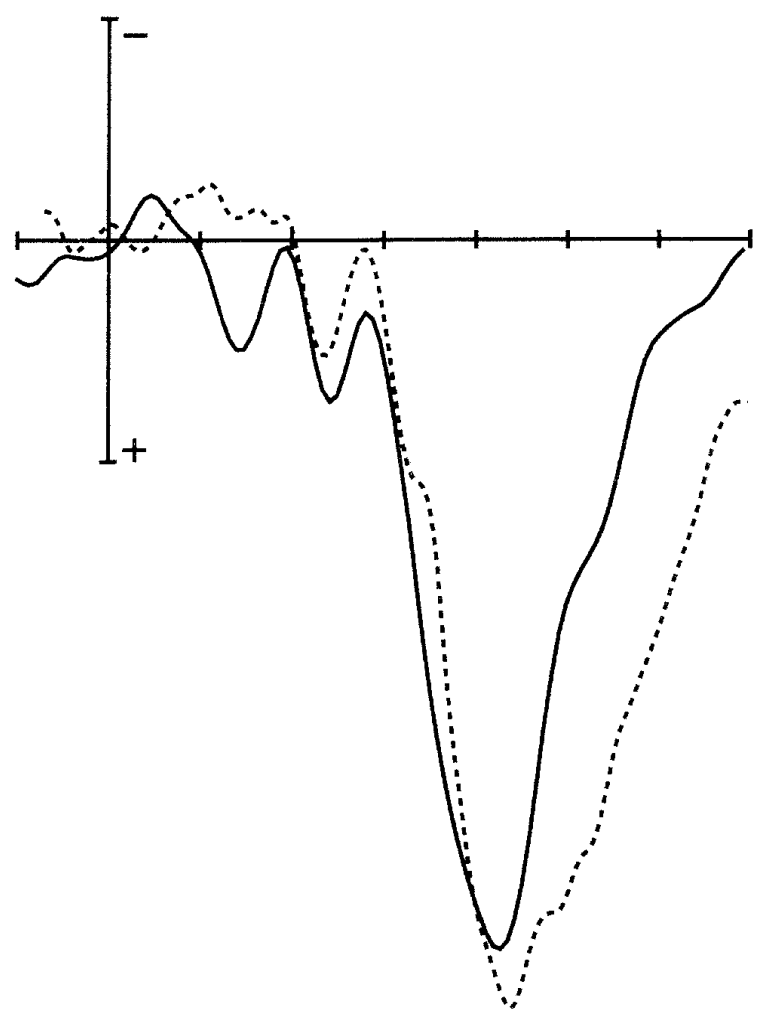

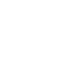


nation of odors and while perceptual odor deficits after left and right temporal lesions have also been observed [30]. The occipital cortex is known to be related to visual processes. Nonetheless, there was no visual field defect. Furthermore, a more detailed analysis of the early occipital C1-, P1- and N1-components of the vERP which are assumed to be generated in striate and prestriate visual cortex (e.g., [10, 29], analysis not show above) did not show any hemispheric differences in S.M.H. Thus, there is no clinical or experimental support for a deficit resulting from the left hemispheric frontal and occipital lesions. Rather, it appears that the right perisylvian lesion was the cause of S.M.H.'s auditory dysfunction. This contrasts our assumptions that a right hemispheric lesion in a professional musician possessing the absolute pitch would be compensated by intact left hemispheric functions as had been derived from the results of studies in healthy musicians (e.g., [2, 6, 8]). Furthermore, our data are evidence against the assumption that absolute pitch is a strong a left hemispheric function as has been suggested by Schlaug et al. [70] after the analysis of planum temporale asymmetries. Rather, our findings are in accordance with the results of Zatorre [91] who showed a person with intact absolute pitch after left temporal lobectomy.

In the literature all patients described with an isolated sound agnosia $(n=5)$ had right temporal or parietal lesions. Most patients with sound agnosia associated with word deafness had bilateral temporal lesions (e.g., $[1,65,86])$. In contrast, the lesions seen in patients with impaired musical functions are not of such a uniform location. Peretz [55] reported that patients with right hemispheric lesions showed a reduction in the detection of melodies and intervals, whereas nonmusicians with left sided lesions were able to detect melodies but not intervals [68, 90]. McFarland and Fortin [47], Takeda [78] and Confavreux [11] report amusias due to right temporal and/or parietal pathologies whereas Wertheim and Botez [85] and Hofman et al.'s [24] amusical patients had left cortical strokes. In summary, sound agnosia and disturbed musical functions have been attributed to right but also to left hemispheric lesions. These findings lead to the hypothesis that the processing of musical information requires a complex interaction between both hemispheres and more than one cortical region within each hemisphere. Such an assumption is partly supported by the data of Engelien et al. [16] showing bilateral cortical activation after recovery from auditory agnosia.

\subsection{Patient's deficits underlying auditory agnosia/amusia}

Concerning the nature of auditory agnosia there has been a dissociation between disturbed perceptual processes (apperceptive agnosia) and disturbed recognition (associative agnosia; e.g., [43, 75]). Associative agnosia refers to patients who cannot recognize familiar sounds due to disturbances in memory representations while the elementary perceptual analysis is undisturbed. Such disabilities have been described for environmental sounds, human voices and familiar tunes (e.g., [17, 75, 76, 80, 84]) and refer to problems at rather 'late' stages of auditory processing. In contrast, apperceptive agnosia refers to patients with difficulties discriminating the acoustic structure of the stimuli, thus demonstrating disturbed perceptual processes (e.g., $[19,56])$ and implicates an impairment at 'early' stages of processing.

Some information about the timecourse of auditory processing in S.M.H. and the underlying deficits can be derived from the ERP-experiments and the results of the Seashore Test.

All assessed categories of the Seashore Test were severely impaired in S.M.H. after the stroke and only partly recovered. One year after the stroke, the results of the subtests timbre test and rhythm test were better than the results of the loudness test and time test. Whereas the former two tests require to decide whether two serially presented sounds are the same or different, the latter two tests involve the more complex categorization of the second stimulus relative to the first one (louder or softer, longer or shorter). Therefore, it can be concluded that S.M.H. had more problems in the complex tasks. Requiring the same stimulus categorizations the performance of the pitch subtest improved more than of the loudness and time discrimination subtests $(24 \%$ vs. $10 \%$ and $12 \%$, respectively). Although this difference is small it shows that the former musical functions recovered more than the latter and supports a functional dissociation of these functions which has already been supposed by others $[56,55]$. All subtests require the perception of the stimulus material and the comparison to a second sound or series of sounds in short term memory. This is a task which hardly involves only perceptual properties as has been assumed by others [19] but rather, to a certain degree, also target evaluation processes. Thus, analyzing the test performance of S.M.H. again demonstrates the impairment of auditory abilities but does not really contribute to the differentiate between 
disturbed perception/recognition processes. However, the test results show that S.M.H.'s inability to name the sounds he heard cannot be attributed to a functional disconnection between perception and naming because in this case one would expect the Seashore Test not to be grossly impaired.

Several reports have associated the N1-ERP-component with primary auditory cortex processes and located the N1-generators within the according superior temporal gyrus (e.g., [39, 42, 54, 82]). The control subjects' N1-components to standard stimuli had a fronto-central maximum and were bilaterally symmetrical. In comparison, S.M.H.'s N1 was located over the same brain region but was slightly reduced over the right hemisphere and bilaterally had a longer latency. Because a quantitative evaluation of the N1 is problematic in a single case study we employed the calculation of isovoltage maps and conducted a BESAanalysis. These isovoltage maps were comparable between S.M.H. and controls and showed a maximal activity at frontocentral scalpsites. Within the control group the BESA-analysis showed two dipoles which were located in the two upper temporal gyri to explain $96.5 \%$ of the variance. This solution is in accordance to the existing literature (e.g., [39, 42, 54, 82]). Using this solution on S.M.H.'s data the dipoles were able to explain $94.3 \%$ of the variance. Thus, although there have been reports about normal middle and long latency auditory ERPs in patients with lesions of the temporal lobes (e.g., [53, 63, 87]) the BESA solution is a strong support for an undisturbed information processing within the primary auditory area in S.M.H. In contrast, later ERP components, which have been associated with later stages of cognitive processing, showed to be partly abnormal in S.M.H. Two of these later ERP components are a frontally distributed negative going wave, which peaks around 200 to $250 \mathrm{~ms}$, the 'N2' component, and a more centro-parietally distributed positivity peaking approximately 300 to 600 $\mathrm{ms}$ after stimulus presentation, the 'P3b' component (e.g., [18, 57, 60, 61, 62, 67]). The N2 is thought to be the earliest electrophysiological instance of target discrimination (e.g., $[18,67]$ ), while the P3b is thought to be related to later target evaluation processes (e.g., [83]). When task irrelevant stimuli of a different acoustic structure such as honking of a car or barking of a dog (novels) are interspersed into the sequence, these are known to elicit the P3a ERP component of more anterior scalp distribution and of earlier peak latency than the P3b (e.g., [12, 21, 25, 34, 48, 67]). It has been hypothesized that the P3a is a sign of the invol- untary capture of attention by deviant stimuli outside the focus of attention (e.g., [21, 49]). Although the P3a component was somewhat reduced over the right hemisphere it can be taken as evidence that S.M.H. perceived the differences between standards/targets and novels well enough so that the novels captured attention. In contrast, the P3b absent 10 weeks after the onset of symptoms and increased in parallel to S.M.H.'s auditory abilities during rehabilitation. vERP recordings showed large P3b components over both hemispheres even 10 weeks after the stroke. This excludes the possibility that the $\mathrm{P} 3 \mathrm{~b}$ reduction in the auditory ERP was caused by damage to one supramodal neural P3b generator but rather demonstrates that the reduction was related to the auditory deficits implicating defect target detection processes which occur at rather late stages of cognitive processing. In summary, the ERP recordings in this patient support a normally functioning primary auditory area as indexed by the $\mathrm{N} 1$, a perception of deviant stimuli (P3a) but disturbed target evaluation processes ( $\mathrm{P} 3 \mathrm{~b})$. Thus, there is electrophysiological evidence for an impairment of recognition processes rather than for perceptual problems.

\subsection{Implications for cortical auditory disorders}

There has been a considerable debate about the classifications of cortical auditory disorders. In the detailed descriptions of their patients Mendez et al. [46] and Peretz et al. [56] show that frequently there is a considerable overlap between disorders involving different aspects of auditory functions such as cortical deafness, auditory agnosia, word deafness and amusia. Many other reports about patients with 'pure' disturbances are limited to a restricted investigation of these patients. There have been, for example, several reports of amusia without other auditory deficits (e.g., $[13,14,36,47])$, but the patients have frequently only been investigated for language impairments but not for sound agnosias. Furthermore, none of the few reports of isolated sound agnosias sufficiently assessed the question of a concurrent amusia [19, 41, 50, 76, 88]. Selective verbal disorders (e.g., [77, 89]) have also been reported by some authors. Combinations of word deafness with either sound agnosia or amusia has been reported before (e.g., [20, 22, 23, 33, 74]). This patient presented with a combination of sound agnosia and amusia without any evidence for word deafness or aphasia. Such a combination of disabilities has only rarely been described before (e.g., [17]). Thus, this case supports the weak evidence for a dissociation of 
musical functions and other cortical auditory disorders. This also adds to the growing evidence that nonverbal auditory disturbances can be separated from verbal disorders and that sound perception and musical functions are two separate features, as has been proposed by others (for an extensive review, see [56]). To further delineate associations between sound agnosia and amusia it seems necessary to develop better tools for the analysis of sound agnosia. So far, all studies published have presented a number of non-verbal sounds to the patients with their task being to indicate the meanings of the sounds heard. This is a rather complex analysis as it involves the perception of different 'local' sound frequencies as different stimulus aspects, their internal conjunction to one 'global' stimulus and the association of these stimulus characteristics with memorized sounds. In contrast, musical abilities such as pitch or rhythm perception have separately been analyzed in detail. Thus, to compare separate musical functions to the perception of other non-verbal sound characteristics it seems important to fractionate the auditory features of non-musical sounds so that they can be assessed separately but also in conjunction and in relation to musical characteristics.

This patient's deficits of the sensory musical functions have also been paralleled by productive problems as he had problems in both vocal and instrumental musical production. This was true for the initial phase as after partial recovery 1 year after the stroke. Thus, it seems difficult to assess the question if both dysfunctions are due to a disturbance of one common neural mechanism. There has been weak evidence about a dissociation between productive and sensory musical function in the existing literature. This is partially due to the low number of amusias which have been described in musicians (e.g., $[45,47,78,85])$ as compared to the majority of cases with poorly developed musical functions. Takeda et al.'s [78] and McFarland and Fortin's [47] patients presented mainly with disturbances of expressive musical functions, while sensory musical functions were relatively preserved. Others report patients with predominantly impaired sensory musical functions (e.g., [85]). It remains to be shown if this dissociation between the two modalities parallels findings in the language domain where different types of aphasia have been described [26, 58].

\section{Acknowledgements}

The authors wish to thank M.D. Rugg for providing the auditory stimuli, I. Peretz, K. Paller and E. Al- tenmüller for critical reviews and Wolfgang Dillo, Wilhelm Johannes and Gregor Joppich for technical support.

\section{References}

[1] M.L. Albert, R. Sparks and T. Von Stockert, A case of auditory agnosia: linguistic and non-linguistic processing, Cortex $\mathbf{8}$ (1972), 427-433.

[2] E. Altenmüller, R. Beisteiner, W. Lang, G. Lindinger, L. Deecke, Cortical activation patterns during perception and imagination of rhythm in professional musicians: a DCpotential study, Neuropsychologia, in revision.

[3] S.H. Auerbach, T. Allard, M. Naeser, M.P. Alexander and M.L. Albert, Pure word deafness: analysis of a case with bilateral lesions and a defect at the prephonemic level, Brain 105 (1982), 271-300.

[4] P. Auzou, F. Eustache, P. Etevenon, H. Platel, P. Rioux, J. Lambert, B. Lechevaliert, E. Zarifian and J.C. Baron, Topographic EEG activations during timbre and pitch discrimination tasks using musical sounds, Neuropsychologia 33 (1995), 25-37.

[5] M. Behrmann, M. Moscovitch and G. Winocur, Intact visual imagery and impaired visual perception in a patient with visual agnosia, Journal of Experimental Psychology: Human Perception and Performance 20 (1994), 1068-1087.

[6] R. Beisteiner, E. Altenmüller, W. Lang, G. Lindinger and L. Deecke, Musicians processing music: measurement of brain potentials with EEG, European Journal of cognitive Psychology 6 (1994), 311-327.

[7] P. Bernard, De l'aphasie et de ses diverses formes, Lecrosnier et Babe, Paris, 1889.

[8] T. Bever and R. Chiarello, Cerebral Dominance in Musicians and Nonmusicians, Science 185 (1974), 537-539.

[9] J.F. Brick, J.L. Frost, S.S. Schochet, L. Gutman and T.W. Crosby, Pure word deafness: CT localization of the pathology, Neurology 35 (1985), 441-442.

[10] V.P. Clark, S. Fan and S.A. Hillyard, Identification of early visual evoked potential generators by retinotopic and topographic analysis, Human Brain Mapping, in press.

[11] C. Confavreux, B. Croisile, P. Garassus, G. Aimard and M. Trillet, Progressive Amusia and Aprosody, Archives of Neurology 49 (1992), 971-976.

[12] E. Courchesne, S.A. Hillyard and R. Galambos, Stimulus novelty, task relevance and the visual evoked potential in man, Electroencephalography and Clinical Neurophysiology 39 (1975), 131-143.

[13] C. Dorgeuille, Introduction a l'étude des amusies. Dissertation, Paris.

[14] J.G. Edgren, Amusi (musikalische Aphasie), Deutsche Zeitschrift für Nervenheilkunde 6 (1895), 1-64.

[15] K. Endo, M. Miyaska, H. Makishita, N. Yanagisawa and M. Sugishita, Tactile agnosia and tactile aphasia: symptomatological and anatomical differences, Cortex 28 (1992), 445469.

[16] A. Engelien, D. Silbersweig, E. Stern, W. Huber, W. Döring, C. Frith and R.S.J. Franckowiak, The junctional anatomy of recovery from auditory agnosia. A PET study of sound categorization in a neurological patient and normal controls, Brain 118 (1995), 1395-1409. 
[17] F. Eustache, B. LeChevalier, F. Viader and J. Lambert, Identification and discrimination disorders in auditory perception: a report on two cases, Neuropsychologia 28 (1990), 257-270.

[18] P.G. Fitzgerald and T.W. Picton, Event-related potentials during the discrimination of improbable stimuli, Biological Psychology 17 (1983), 241-276.

[19] T. Fujii, R. Fukatsu, S. Watabe, A. Ohnuma, K. Teramura I. Kimura, S. Shun-ichi and K. Kogure, Auditory sound agnosia without aphasia following a right temporal lobe lesion, Cortex 26 (1990), 263-268.

[20] J. Graham, R. Greenwood and B. Lecky, Cortical deafness. A case report and review of the literature, Journal of Neurological Sciences 48 (1980), 35-49.

[21] F.K. Graham and S.A. Hackley, Passive attention and generalized orienting, in: Handbook of Cognitive Psychophysiology: Central and Autonomic Nervous System Approaches, J.R. Jennings and M.G.H. Coles, eds, Wiley, Chichester, 1991, pp. 253-299.

[22] O. Guard, J.F. Couiller and R. Dumas, Agnosie auditive, Lyon Medicine 243 (1980), 211-317.

[23] R.E. Hemphill and E. Stengel, A study on pure worddeafness, Journal of Neurology, Neurosurgery and Psychiatry 3 (1940), 251-262.

[24] S. Hofman, C. Klein and A. Arlazoroff, Common hemisphericity of language and music in a musician. A case report, Journal of Communication Disorders 26 (1993), 73-82.

[25] J.H. Holdstock and M.D. Rugg, Dissociation of auditory P300: differential brain response to target and novel stimuli, in: New Developments in Event-related potentials, $\mathrm{H}$ Heinze, T. Münte and G.R. Mangun, eds, Birkhäuser, Boston, , pp. ??-??.

[26] W. Huber, K. Poeck and K. Willmes, The Aachen Aphasia Test (AAT), Advances in Neurology 42 (1984), 291-303.

[27] H. Jasper, The ten twenty system of the international federation, Electroencephalography and Clinical Neurophysiology 10 (1958), 371-375.

[28] S. Johannes, U. Knälmann, G.R. Mangun, H.J. Heinze and T.F. Münte, The visual C1 component: scalp topography, dipole sources and effects of luminance and spatial attention, in: Mapping Cognition in Time and Space, H.J. Heinze, T.F. Münte, G.R. Mangun and H. Scheich, eds, Birkhäuser, Boston, (in press), pp. ??-??.

[29] S. Johannes, A. Weber, K.R. Müller-Vahl, H. Kolbe, R. Dengler and T.F. Münte, Event-related brain potentials show changed attentional mechanisms in Gilles de la Tourette Syndrome, Eur J Neurol, (in press).

[30] M. Jones-Gotman and R.J. Zatorre, Olfactory identification deficits in patients with focal cerebral excision, Neuropsychologia 26 (1988), 387-400

[31] D. Kimura, Cerebral dominance and the perception of verbal stimuli, Canadian Journal of Psychology 15 (1961), 166171.

[32] D. Kimura, Left-right differences in the perception of melodies, Quarterly Journal of Experimental Psychology 16 (1964), 355-358.

[33] R. Klein and J. Harper, The problem of agnosia in light of a case of pure word deafness, Journal of Mental Sciences $\mathbf{1 0 2}$ (1956), 112-120.

[34] R.T. Knight, Decreased response to novel stimuli after prefrontal lesions in humans, Electroencephalography and Clinical Neurophysiology 59 (1984), 9-20.

[35] A. Knoblauch, Über Störungen der musiklischen Leistungsfähigkeit infolge von Gehirnläsionen, Dtsche Archive für Klinische Medizin 43 (1888), 331-345.
[36] G.F. Kohl and H. Tschabitscher, Über einen Fall von Amusie, Wiener Zeitschrift für Nervenheilkunde und Grenzgebiete 6 (1953), 219-230.

[37] I. Koizuka, H. Yano, M. Nagahara, R. Mochizuki, R. Seo, K. Shimada, T. Kubo and T. Nogawa, Functional imaging of the human olfactory cortex by magnetic resonance imaging, Journal of Otorhinolaryngology and Related Specialities $\mathbf{5 6}$ (1994), 273-275.

[38] B. Kolb, B. Wilson and L. Taylor, Developmental changes in the recognition and comprehension of facial expression: implications for frontal lobe function, Brain and Cognition 20 (1992), 74-84.

[39] S. Kuriki and M. Murase, Neuromagnetic study of the auditory responses in right and left hemispheres of the human brain evoked by pure tones and speech sounds, Experimental Brain Research 77 (1989), 127-134.

[40] A. Kussmaul, Disturbances of speech, in: Cyclopedia of the Practice of Medicine, $\mathrm{H}$. von Ziemssen, ed., New York, William Wood, 1877, pp. 581-875.

[41] J. Lambert, F. Eustache, B. LeChevalier, Y. Rossa and F. Viader, Auditory agnosia with relative sparing of speech perception, Cortex 25 (1989), 71-82.

[42] C. Liegeois-Chauvel, A. Musolino, J.M. Badier, P. Marquis and P. Chauvel, Evoked potentials recorded from the auditory cortex in man: evaluation and topography of the middle latency components, Electroencephalography and Clinical Neurophysiology 92 (1994), 204-214.

[43] H. Lissauer, Ein Fall von Seelenblindheit nebst einem Beitrag zur Theorie derselben, Archive für Psychie und Nervenkrankheiten 21 (1890), 222-270.

[44] L. Lichtheim, On aphasia, Brain 7 (1885), 433-484.

[45] L. Mavlov, Amusia due to rhythm agnosia in a musician with left hemisphere damage: a non-auditory supramodal defect, Cortex 16 (1980), 331-338.

[46] M.F. Mendez and G.R. Geehan, Cortical auditory disorders: clinical and psychoacoustic features, Journal of Neurology, Neurosurgery and Psychiatry 51 (1988), 1-9.

[47] H.R. McFarland and D. Fortin, Amusia due to right temporoparietal infarct, Archives of Neurology 39 (1982), 725727.

[48] T.F. Münte, D. Berger, C. Terkamp, C. Schöfl, S. Johannes and G. Brabant, Cognitive functioning in experimental hypoglycemia assessed with event-related potentials, Neuroreport 6 (1995), 1509-1512.

[49] R. Näätänen, The role of attention in auditory information processing as revealed by event-related brain potentials and other brain measures of cognitive function, Behavioural Brain Sciences 13 (1990), 201-288.

[50] J.M. Nielsen and C.W. Sult, Agnosias and the body scheme, Bulletin of the Los Angeles Neurological Society 4 (1939), 69-81.

[51] R.C. Oldfield, The assessment and analysis of handedness: the Edinburgh Inventory, Neuropsychologia 9 (1971), 97113.

[52] H. Oppenheim, Über das Verhalten der musikalischen Ausdrucksbewegungen und des musikalischen Verständnisses bei Aphatischen, Annalen des Charité-Krankenhauses zu Berlin 13 (1886), 345-383.

[53] A. Parving, G. Salomon, C. Elberling, B. Larsen and N.A. Lassen, Middle components of the auditory evoked response in bilateral temporal lobe lesions, Scandinavian Audiology 9 (1980), 161-167.

[54] R.D. Pascual-Marqui, C.M. Michel and D. Lehmann, Low resolution electromagnetic tomography: a new method for lo- 
calizing electrical activity in the brain, International Journal of Psychophysiology 18 (1994), 49-65.

[55] I. Peretz, Processing of local and global musical information by unilateral brain-damaged patients, Brain 113 (1990), 1185-1205.

[56] I. Peretz, R. Kolinsky, M. Tramo, R. Labrecque, C. Hublet, G. Demeurisse and S. Belleville, Functional dissociations following bilateral lesions of auditory cortex, Brain 117 (1994), 1283-1301.

[57] T.W. Picton, The P300 wave of the human event-related potential, Journal of Clinical Neurophysiology 9 (1992), 456479.

[58] K. Poeck, R. De Bleser and D.G. Von Keyserlingk, Computed tomography localization of standard aphasic syndromes, $\mathrm{Ad}$ vances in Neurology 42 (1984), 71-89.

[59] E. Poggio, Die korticale Lokalisation der Asymbolie, $\mathrm{Neu}$ rologisches Zentralblatt 27 (1908), 817-818.

[60] J. Polich, Probability and inter-stimulus interval effects on the P300 from auditory stimuli, International Journal of Psychophysiology 10 (1990), 163-170.

[61] J. Polich and H.K. McIsaac, Comparison of auditory P300 habituation from active and passive conditions, International Journal of Psychophysiology 17 (1994), 25-34.

[62] J. Polich, T. Brock and M.W. Geisler, P300 from auditory and somatosensory stimuli: probability and inter-stimulus interval, International Journal of Psychophysiology 11 (1991), 219-223.

[63] P. Praamstra, P. Hagoort, B. Maassen and T. Crul, Word Deafness and auditory cortical function, Brain 114 (1991), 1197-1225.

[64] C.L. Reed and R.J. Caselli, The nature of tactile agnosia: a case study, Neuropsychologia 32 (1994), 527-539.

[65] G. Rosati, P. Bastiani and E. Paolino, Clinical and audiological findings in a case of auditory agnosia, Journal of Neurology 227 (1982), 21-27.

[66] M.D. Rugg, C.P. Cowan, M.E. Nagy, A.D. Milner, I. Jacobson and D.N. Brooks, Event-related potentials from closed head injury patients in a auditory 'oddball' task: evidence of dysfunction in stimulus categorisation, Journal of Neurology, Neurosurgery and Psychiatry 51 (1988), 691-698.

[67] M.D. Rugg, C.D. Pickles, D.D. Potter, M.C. Doyle, B. Pentland and R.C. Roberts, Cognitive brain potentials in a threestimulus auditory 'oddball' task after closed head injury, $\mathrm{Neu}$ ropsychologia 31 (1993), 373-393.

[68] S. Samson and R. Zatorre, Melodic and harmonic discrimination following unilateral cerebral excision, Brain and Cognition 7 (1988), 348-360.

[69] M. Scherg, Fundamentals of dipole source potential analysis, in: Auditory Evoked Magnetic Field and Potentials. Advances in Audiology 6, F. Grandori, M. Hoke and G.L. Romani, eds, Karger, Basel, 1990, pp. 40-69.

[70] G. Schlaug, L. Jäncke, Y. Huang and H. Steinmetz, In vivo evidence of structural brain asymmetry in musicians, Science 267 (1994), 699-701.

[71] A.D. Schnider, F. Benson and D.W. Scharre, Visual agnosia and optic aphasia: are they anatomically distinct?, Cortex 30 (1994), 445-457.

[72] Seashore-Test für musikalische Begabung. C. Butsch and $\mathrm{H}$ Fischer, eds, Huber, Bern, 1966.
[73] I. Shimoyama, T. Ninchoji and K. Uemura, The FingerTapping Test. A quantitative Analysis, Archives of Neurology 47 (1990), 681-684.

[74] J.J. Sidtis, Music, pitch perception, and the mechanism of cortical hearing, in: Cognitive Neurosciences, M. Gazzaniga, ed., pp. 91-114.

[75] H. Spinnler and L.A. Vignolo, Impaired recognition of meaningful sounds in aphasia, Cortex 2 (1966), 227-348.

[76] O. Spreen, A.L. Benton and R.W. Fincham, Auditory agnosia without aphasia, Archives of Neurol 13 (1965), 84-92.

[77] N. Takahashi, M. Kawamura, H. Shinotou, K. Hirayama, K. Kaga and M. Shindo, Pure word deafness due to left hemisphere damage, Cortex 28 (1992), 295-303.

[78] K. Takeda, M. Bandou and Y. Nishimura, Motor amusia following a right temporal lobe hemorrhage - a case report, Rinsho-Shinkeigaku 30 (1990), 78-83.

[79] J. Talairach and P. Tournoux, Co-planar stereotaxic atlas of the human brain, Thieme, Stuttgart, 1988.

[80] D. Van Lancker and J. Kreiman, Voice discrimination and recognition are separate abilities, Neuropsychologia $\mathbf{2 5}$ (1987), 829-834.

[81] F. Vargha-Khadem, E. Isaacs and M. Mishkin, Agnosia, alexia and a remarkable form of amnesia in an adolescent boy, Brain 117 (1994), 683-703.

[82] C. Verkindt, O. Bertrand, F. Perrin, J.F. Echallier and J. Pernier, Tonotopic organization of the human auditory cortex: N100 topography and multiple dipole model analysis, Electroencephalography and Clinical Neurophysiology 96 (1995), 143-156.

[83] R. Verleger, A critique of the context updating hypothesis and an alternative interpretation of P3, Behavioural Brain Sciences 11 (1988), 343-427.

[84] L. Vignolo, Auditory agnosia, Philosophical Transactions of the Royal Society of London Biologists 298 (1982), 49-57.

[85] N. Wertheim and M.I. Botez, Receptive amusia: a clinical analysis, Brain 84 (1961), 19-30.

[86] G. Wohlfahrt, A. Lindgren and B. Jernelins, Clinical picture and morbid anatomy in a case of 'pure word deafness', Journal of Nervous and Mental Disorders 116 (1952), 818-827.

[87] D.L. Woods, R.T. Knight and H.J. Neville, Bitemporal lesions dissociate auditory evoked potentials and perception, Electroencephalography and Clinical Neurophysiology $\mathbf{5 7}$ (1984), 208-220.

[88] S.B. Wortis and A.Z. Pfeffer, Unilateral auditory-spatial agnosia, Journal of Nervous and Mental Disorders 108 (1948), 181-186.

[89] B.A. Yaqub, G.G. Gascon, M. Alnosha and H. Whitaker, Pure word deafness (Acquired verbal auditory agnosia) in an arabic speaking patient, Brain 111 (1988), 457-466.

[90] R.J. Zatorre, Discrimination and recognition of tonal melodies after unilateral cerebral excisions, Neuropsychologia $\mathbf{2 3}$ (1985), 31-41.

[91] R.J. Zatorre, Intact absolute pitch ability after left temporal lobectomy, Cortex 25 (1989), 567-580.

[92] R.J. Zatorre and M. Jones-Gotman, Right-nostril advantage for discrimination of odors, Perception and Psychophysics $\mathbf{4 7}$ (1990), 526-531.

[93] R.J. Zatorre, A.C. Evans and E. Meyer, Neural mechanisms underlying melodic perception and memory for pitch, Journal of Neuroscience 14 (1994), 1908-1919. 


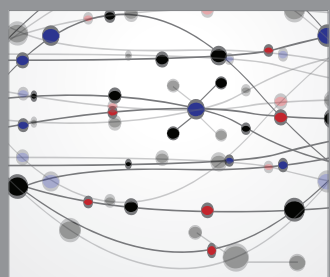

The Scientific World Journal
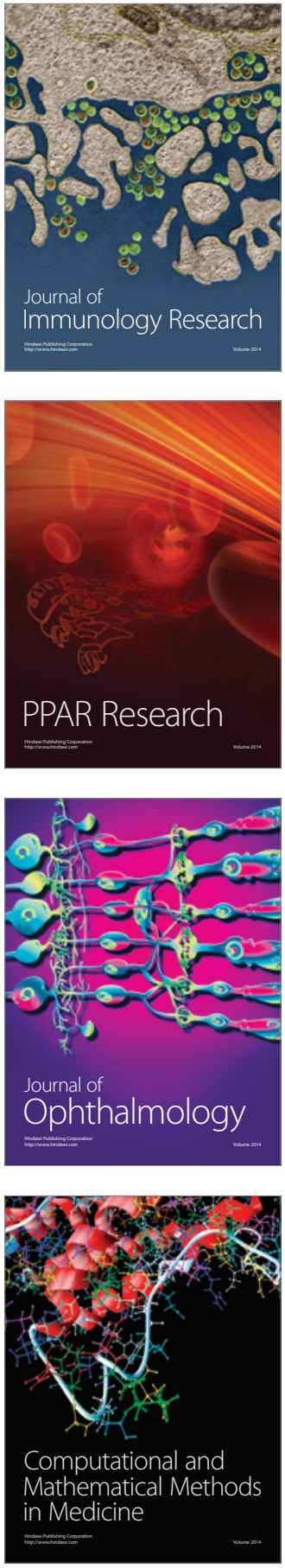

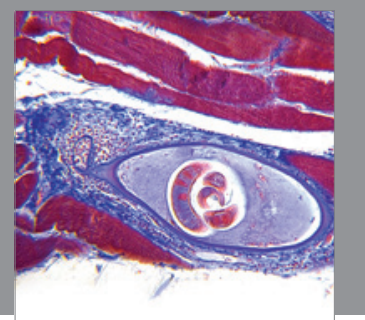

Gastroenterology

Research and Practice
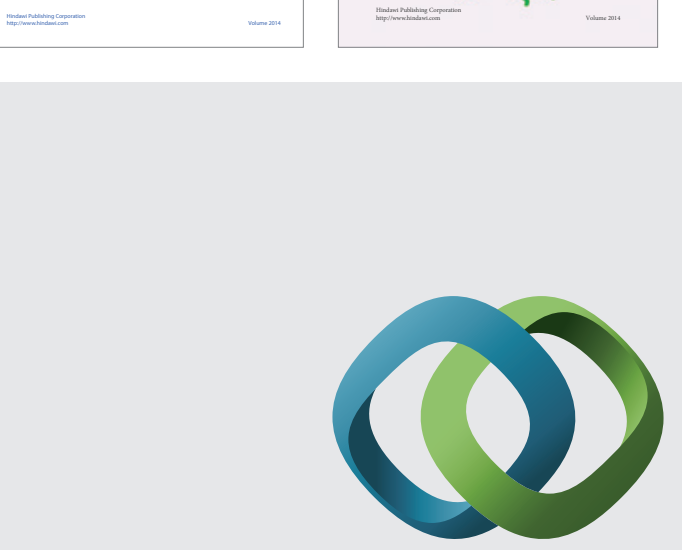

\section{Hindawi}

Submit your manuscripts at

http://www.hindawi.com
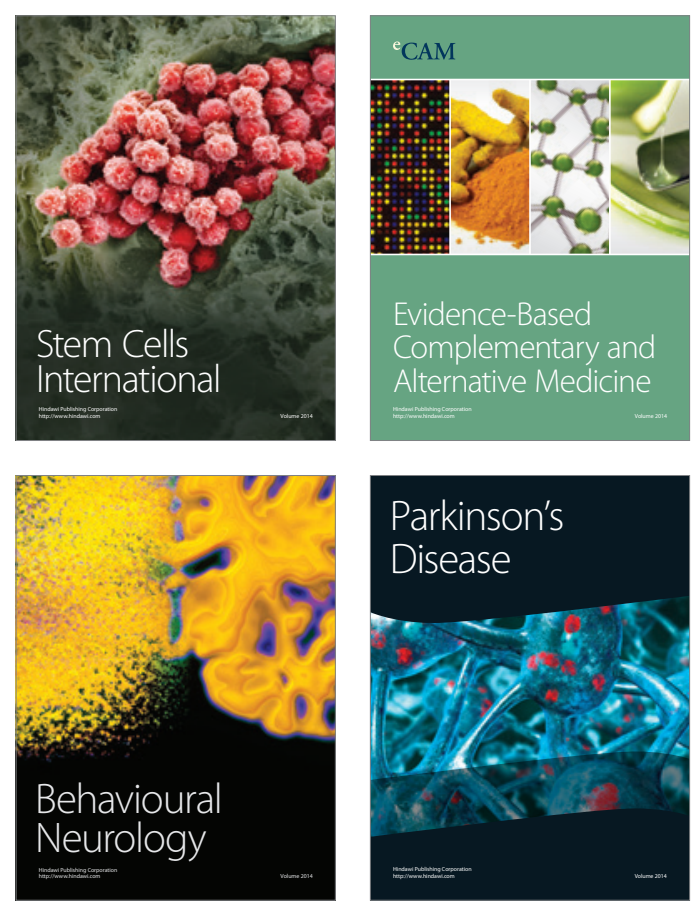

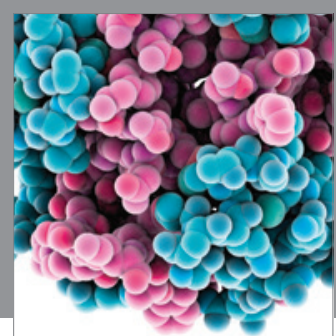

Journal of
Diabetes Research

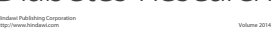

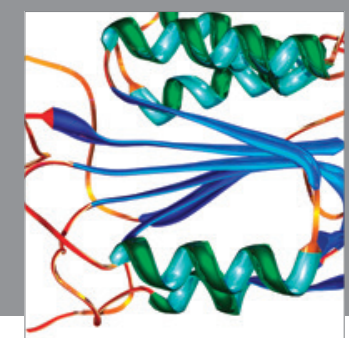

Disease Markers
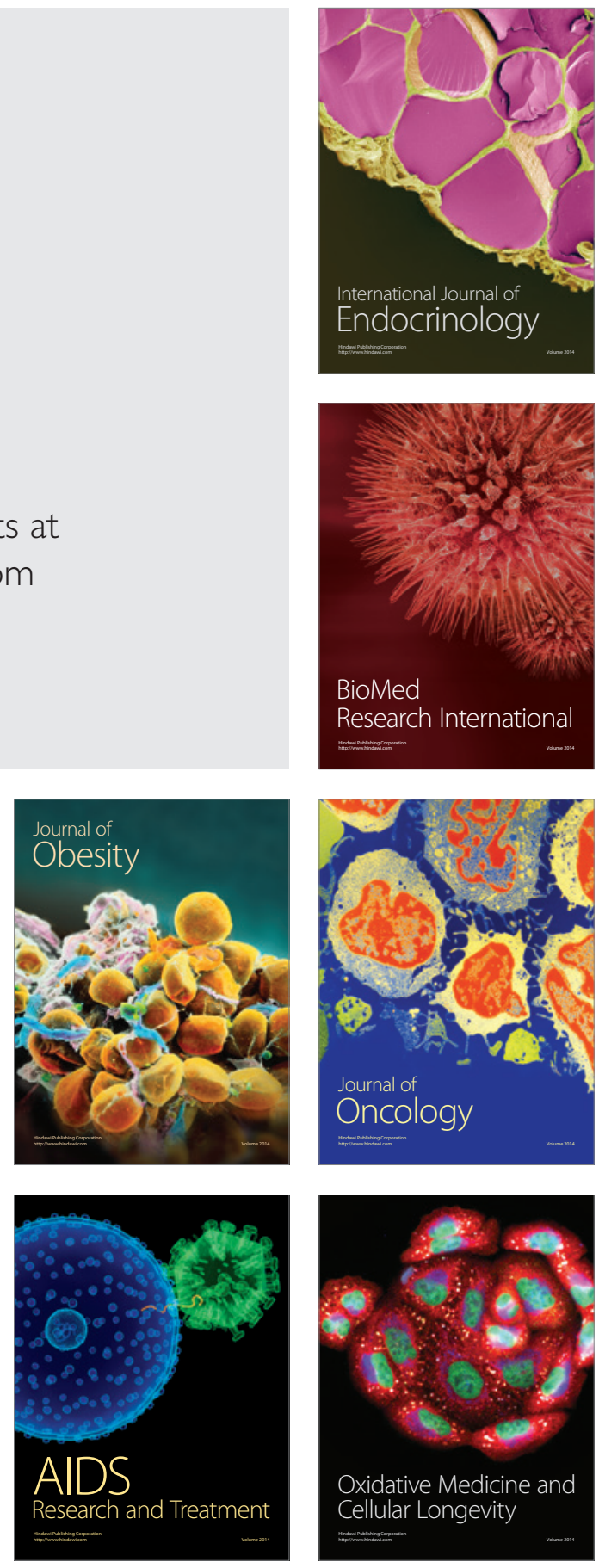